\title{
Characterization of the Expression and Functions of Two Odorant-Binding Proteins of Sitophilus zeamais Motschulsky (Coleoptera: Curculionoidea)
}

\author{
Ying Zhang ${ }^{1,+}$, Chen Shen ${ }^{1,+}$, Daosong Xia ${ }^{1}$, Jian Wang ${ }^{2}$ and Qingfeng Tang ${ }^{1, *(\mathbb{B})}$ \\ 1 Key Laboratory of Biology and Sustainable Management of Plant Diseases and Pests of Anhui Higher \\ Education Institutes, College of Plant Protection, Anhui Agricultural University, Hefei 230036, Anhui, China; \\ zhangying60416@163.com (Y.Z.); shenchen2506@163.com (C.S.); xiadaosong_25@163.com (D.X.) \\ 2 Department of Entomology, University of Maryland, College Park, MD 20742, USA; jianwang@umd.edu \\ * Correspondence: tangqf55@163.com; Tel.: +86-551-65786321 \\ $+\quad$ Ying Zhang and Chen Shen contributed equally to this work.
}

Received: 25 September 2019; Accepted: 14 November 2019; Published: 15 November 2019

\begin{abstract}
Odorant-binding proteins (OBPs) are important in insect chemical communication. The objective of this research was to identify the functions of two OBPs in Sitophilus zeamais. qRT-PCR and western blot (WB) were performed to investigate the expression profiles at the transcript and protein levels, respectively. Fluorescence competitive binding assays were used to measure the ability of the OBPs to bind to host volatiles, and a Y-tube olfactometer was used to verify the results (attraction/no response) via behavioral experiments. The RNAi was used to verify the function by knocking down the ability of proteins to bind odorants. qRT-PCR showed the highest expression SzeaOBP1 and SzeaOBP28 at the low-instar larva (LL) and eclosion adult (EA) stages, respectively. WB showed that both SzeaOBP1 and SzeaOBP28 were highly expressed in the EA stage. Fluorescence competitive binding assays indicated that SzeaOBP1 exhibited extremely high binding affinity with cetanol. SzeaOBP28 exhibited a pronounced binding affinity for 4-hydroxy-3-methoxybenzaldehyde. The behavioral experiment showed that the adult S. zeamais responded strongly to 4-hydroxy-3-methoxybenzaldehyde and valeraldehyde from Sorghum bicolor. The RNAi knockdown individuals displayed behavioral differences between normal insects and dsRNA (SzeaOBP1)-treated insects. We infer that they both have functions in perception and recognition of host volatiles, whereas SzeaOBP28 may also have other functions.
\end{abstract}

Keywords: Sitophilus zeamais; odorant-binding protein; expression pattern; host volatiles; ligand-binding spectrum; RNA interference; behavioral responses

\section{Introduction}

Insect olfaction has been a longstanding subject of scientific research aimed at understanding and identifying methods for controlling pest insects [1-4]. Detection of chemical signals from the environment via olfaction is an indispensable mechanism for the maintenance of an insect's life, inducing critical behavioural responses at vital times. Insects can detect host or food volatiles in relatively complex environments, which plays an important role in the process of food localization by insects via the detection of plant volatiles. An understanding of the biological phenomena involved in the whole process of olfactory signal transduction in insects will not only aid the comprehension of host identification and other life activities of insects, but also facilitate the development of new and improved plant protection strategies [5].

Several researchers have investigated the whole olfactory responses of insects and the underlying mechanisms of olfaction by using odorant-binding proteins (OBPs), which will further the 
understanding of insect life [6-9]. However, relatively little is known regarding the maize weevil OBPs. On the basis of the characteristics of molecular biology, the specific functions of SzeaOBPs remain unknown or unclear. The associations between SzeaOBPs and the perception of host plant odorants and food resource volatiles in maize weevil are of great interest. The OBPs in the insect sensillum lymph play important physiological roles in both insect chemical communication and in survival [4]. OBPs are present as water-soluble proteins in olfactory sensilla. These proteins bind odorant molecules in the sensillum lymph and transport these molecules to olfactory receptors in dendritic membranes that then generate, transmit, and integrate electrical signals, which ultimately guide the insect's response to changes in the external environment. The binding of OBPs to lipid-soluble odorant molecules is a foundational aspect of the communication between insects and their surroundings [10]. Stored-product insects, including the maize weevil, Sitophilus zeamais Motschulsky (Coleoptera: Curculionoidea), are serious pests that affect many agricultural commodities, causing severe postharvest loss via the effects of both live insects and metabolites, with values as high as $9 \%$ in developed countries to $20 \%$ or more in developing countries [11,12]. In conventional control methods, fumigants are generally used to control storage pests in combination with, on the basis of our analysis, insect detoxification enzyme-related genes such as cytochrome P450 (CYP450) and Glutathione S-transferase (GST) [13]. In addition, we searched for ways to use OBPs to control storage pests. In this study, to elucidate the function of SzeaOBP1, chemical ecological techniques and molecular biology were used to investigate this OBP, which was achieved by quantitative real-time PCR of different developmental stages and by comparison of transcriptomic data showing the expression levels in different tissues. Then, expression and purification of target proteins was performed by using a bacterial expression system. A fluorescence competitive binding assay was used to measure the binding of insect proteins to host plant volatiles. RNA interference was used to verify the results.

This study identified the putative functions of SzeaOBP1 and SzeaOBP28 in maize weevil, examined the molecular activity of these proteins and the behavioral responses in maize weevil, and assessed the potential functional application of these proteins for binding or attraction.

\section{Materials and Methods}

\subsection{General Odorants}

The odorants used in this study were chosen from food source volatiles of maize weevil, including host plant seed or grain volatiles. In total, 27 odorants were selected for use in the tests after surveying a sufficient number of literature reports and a large number of preliminary experimental results. All the odorant samples were sourced from Adamas-beta (Shanghai, China), Aladdin (Shanghai, China), or Tokyo Chemical Industry (Tokyo, Japan) at the highest purity available (Table 1).

Table 1. Volatiles from host plants used for fluorescence competitive binding experiments, including reagent name, chemical abstracts service (CAS) number, purity, source, and reference. All the volatiles selected were single compounds that have been reported in the literature.

\begin{tabular}{|c|c|c|c|c|c|c|c|}
\hline Ligand & CAS & Purity (\%) & Source & Origin & Reference & $\begin{array}{c}\text { Molecular } \\
\text { Weight }\end{array}$ & Formula \\
\hline Pentadecane & $629-62-9$ & 99 & Aladdin & S. bicolor & [14] & 212.41 & $\mathrm{C}_{15} \mathrm{H}_{32}$ \\
\hline N-hexadecane & $544-76-3$ & $98+$ & Adamas-beta & S. bicolor & [15] & 226.44 & $\mathrm{C}_{16} \mathrm{H}_{34}$ \\
\hline 1-Nonanol & $143-08-8$ & 98 & Adamas-beta & A. hypogaea & {$[16,17]$} & 144.25 & $\mathrm{C}_{9} \mathrm{H}_{20} \mathrm{O}$ \\
\hline 1-Hexanol & $111-27-3$ & 98 & Adamas-beta & $\begin{array}{c}\text { O. sativa, S. bicolor, } \\
\text { S. italica }\end{array}$ & {$[15,16,18]$} & 102.17 & $\mathrm{C}_{6} \mathrm{H}_{14} \mathrm{O}$ \\
\hline Capryl alcohol & $111-87-5$ & 99 & Adamas-beta & S. bicolor & [15] & 130.23 & $\mathrm{C}_{8} \mathrm{H}_{18} \mathrm{O}$ \\
\hline Cetanol & $36653-82-4$ & $98+$ & Adamas-beta & Storage grain & [19] & 242.44 & $\mathrm{C}_{16} \mathrm{H}_{34} \mathrm{O}$ \\
\hline Decanal & $112-31-2$ & 97 & Adamas-beta & S. bicolor & [15] & 156.27 & $\mathrm{C}_{10} \mathrm{H}_{20} \mathrm{O}$ \\
\hline Valeraldehyde & $110-62-3$ & 98 & Adamas-beta & S. bicolor & {$[14,20]$} & 86.13 & $\mathrm{C}_{5} \mathrm{H}_{10} \mathrm{O}$ \\
\hline Heptaldehyde & $111-71-7$ & 97 & Adamas-beta & O. sativa & [21] & 114.19 & $\mathrm{C}_{7} \mathrm{H}_{14} \mathrm{O}$ \\
\hline $\begin{array}{c}\text { 4-Hydroxy-3- } \\
\text { methoxybenzaldehyde }\end{array}$ & $121-33-5$ & 99 & Adamas-beta & $\begin{array}{c}\text { T. aestivum, O. sativa, } \\
\text { A. ativa, S. cereale, } \\
\text { H. vulgare }\end{array}$ & {$[20,22]$} & 152.15 & $\mathrm{C}_{8} \mathrm{H}_{8} \mathrm{O}_{3}$ \\
\hline
\end{tabular}


Table 1. Cont.

\begin{tabular}{|c|c|c|c|c|c|c|c|}
\hline Ligand & CAS & Purity (\%) & Source & Origin & Reference & $\begin{array}{c}\text { Molecular } \\
\text { Weight }\end{array}$ & Formula \\
\hline 2-Methylbutyraldehyde & $96-17-3$ & $98+$ & Adamas-beta & $\begin{array}{l}\text { S. bicolor, Z. mays, } \\
\text { S. italica }\end{array}$ & [23] & 86.13 & $\mathrm{C}_{5} \mathrm{H}_{10} \mathrm{O}$ \\
\hline Benzaldehyde & $100-52-7$ & 99 & Adamas-beta & O. sativa & {$[24,25]$} & 106.12 & $\mathrm{C}_{7} \mathrm{H}_{6} \mathrm{O}$ \\
\hline Nonanal & $124-19-6$ & $95+$ & $\begin{array}{l}\text { Tokyo } \\
\text { Chemical } \\
\text { Industry }\end{array}$ & $\begin{array}{l}\text { O. sativa, S. bicolor, } \\
\text { A. hypogaea, S. italica }\end{array}$ & {$[26,27]$} & 142.24 & $\mathrm{C}_{9} \mathrm{H}_{18} \mathrm{O}$ \\
\hline n-Octanaldehyde & $124-13-0$ & 98 & Adamas-beta & $\begin{array}{l}\text { O. sativa, } \\
\text { A. hypogaea, }\end{array}$ & {$[16,26]$} & 128.21 & $\mathrm{C}_{8} \mathrm{H}_{16} \mathrm{O}$ \\
\hline 3-Methylbutanal & $590-86-3$ & 98 & Adamas-beta & $\begin{array}{l}\text { O. sativa, S. bicolor, } \\
\text { Z. mays, S. italica }\end{array}$ & [23] & 86.13 & $\mathrm{C}_{5} \mathrm{H}_{10} \mathrm{O}$ \\
\hline Isobutyraldehyde & $78-84-2$ & $98+$ & $\begin{array}{l}\text { Tokyo } \\
\text { Chemical } \\
\text { Industry }\end{array}$ & $\begin{array}{l}\text { O. sativa, S. bicolor, } \\
\text { Z. mays, S. italica }\end{array}$ & [23] & 72.11 & $\mathrm{C}_{4} \mathrm{H}_{8} \mathrm{O}$ \\
\hline 1-Pentanecarbaldehyde & $66-25-1$ & 98 & Adamas-beta & $\begin{array}{l}\text { S. bicolor, O. sativa, } \\
\text { A. hypogaea, S. italica }\end{array}$ & {$[14,16,27]$} & 100.16 & $\mathrm{C}_{6} \mathrm{H}_{12} \mathrm{O}$ \\
\hline 6-Methyl-5-hepten-2-one & $110-93-0$ & 98 & Adamas-beta & O. sativa & [28] & 126.2 & $\mathrm{C}_{8} \mathrm{H}_{14} \mathrm{O}$ \\
\hline Acetone & $67-64-1$ & 98 & Adamas-beta & S. bicolor & [14] & 58.08 & $\mathrm{C}_{3} \mathrm{H}_{6} \mathrm{O}$ \\
\hline 2-Pentanone & $107-87-9$ & 99 & Adamas-beta & O. sativa & [21] & 86.13 & $\mathrm{C}_{5} \mathrm{H}_{10} \mathrm{O}$ \\
\hline Palmitic acid & $57-10-3$ & $98+$ & Adamas-beta & S. bicolor, S. italica & [15] & 256.42 & $\mathrm{C}_{16} \mathrm{H}_{32} \mathrm{O}_{2}$ \\
\hline Linoleic acid & $60-33-3$ & $95+$ & Aladdin & $\begin{array}{l}\text { O. sativa, S. bicolor, } \\
\text { S. italica }\end{array}$ & {$[15,21]$} & 280.45 & $\mathrm{C}_{18} \mathrm{H}_{32} \mathrm{O}_{2}$ \\
\hline Acetic acid (glacial) & $64-19-7$ & 99 & Adamas-beta & Z. mays & [29] & 60.05 & $\mathrm{C}_{2} \mathrm{H}_{4} \mathrm{O}_{2}$ \\
\hline $\begin{array}{l}\text { Maltol (3-hydroxy-2- } \\
\text { methyl-4-pyrone) }\end{array}$ & $118-71-8$ & 99 & Adamas-beta & $\begin{array}{c}\text { T. aestivum, O. sativa, } \\
\text { A. sativa, S. cereale, } \\
\text { H. vulgare }\end{array}$ & [20] & 126.11 & $\mathrm{C}_{6} \mathrm{H}_{6} \mathrm{O}_{3}$ \\
\hline $\begin{array}{l}\text { Myrcene (stabilized } \\
\text { with BHT) }\end{array}$ & $123-35-3$ & $75+$ & Adamas-beta & Storage grain & [19] & 136.23 & $\mathrm{C}_{10} \mathrm{H}_{16}$ \\
\hline $\begin{array}{l}\text { Bis(2-methoxyethyl) } \\
\text { phthalate }\end{array}$ & $117-82-8$ & 95 & Adamas-beta & Storage grain & [19] & 282.29 & $\mathrm{C}_{14} \mathrm{H}_{18} \mathrm{O}_{6}$ \\
\hline Methanol & $67-56-1$ & HPLC & Adamas-beta & - & - & 32.04 & $\mathrm{CH}_{4} \mathrm{O}$ \\
\hline $\begin{array}{c}\text { N-Phenyl-1- } \\
\text { naphthylamine }\end{array}$ & $90-30-2$ & 99 & Adamas-beta & - & - & 219.28 & $\mathrm{C}_{16} \mathrm{H}_{13} \mathrm{~N}$ \\
\hline
\end{tabular}

Notes: Sorghum bicolor (S. bicolor); Arachis hypogaea (A. hypogaea); Oryza sativa (O. sativa); Setaria italica (S. italica); Triticum aestivum (T. aestivum); Avena sativa (A. sativa); Secale cereal (S. cereale); Hordeum vulgare (H. vulgare); Zea mays (Z. mays).

\subsection{Insect Rearing}

The population of maize weevil used in this experiment from a laboratory colony maintained and reared in Entomology Ecology Laboratory, School of Plant Protection, Anhui Agriculture University (Hefei, Anhui, China). The laboratory colony originated from field collection, identification, and culture in the laboratory for more than five generations. The $S$. zeamais insects were reared in glass containers that were $9 \mathrm{~cm}$ in diameter $10 \mathrm{~cm}$ in height. The containers were covered with a plastic cap with a breathable copper mesh in the center and kept at $28 \pm 1{ }^{\circ} \mathrm{C}$ under $80 \%$ relative humidity in total darkness. The experimental population samples were all done by random collection.

\subsection{RNA Extraction and cDNA Synthesis}

Total RNA extraction was performed for each sample using RNAiso Plus (TaKaRa, Dalian, China) according to the manufacturer's instructions. The integrity and purity of the total RNA were analyzed by $1.5 \%$ agarose electrophoresis and a NanoDrop spectrophotometer (Thermo Fisher Scientific, Wilmington, DE, USA). Then, each RNA sample was reverse-transcribed to cDNA using a two-step method with the PrimeScript RT Reagent Kit with gDNA Eraser (TaKaRa, Dalian, China). The first step involved the removal of genomic DNA using $5 \times$ gDNA Eraser buffer $(2.0 \mu \mathrm{L})$, gDNA Eraser $(1.0 \mu \mathrm{L})$, total RNA $(2.0 \mu \mathrm{L})$, and RNase-free $\mathrm{dH}_{2} \mathrm{O}$ up to $10 \mu \mathrm{L}$; the mixture was incubated at $42{ }^{\circ} \mathrm{C}$ for $2 \mathrm{~min}$. Next, reverse transcription was performed to synthesize the first-strand cDNA with the following reagents: step 1 reaction solution $(10.0 \mu \mathrm{L})$, PrimeScript RT enzyme mix I $(1.0 \mu \mathrm{L})$, RT primer mix $(4.0 \mu \mathrm{L}), 5 \times$ PrimeScript buffer $2(4.0 \mu \mathrm{L})$, and RNase-free $\mathrm{dH}_{2} \mathrm{O}(1.0 \mu \mathrm{L})$; the total volume of the system was $20 \mu \mathrm{L}$. Lastly, we incubated the reaction system at $37^{\circ} \mathrm{C}$ for $15 \mathrm{~min}$, followed by incubation at $85^{\circ} \mathrm{C}$ for $5 \mathrm{~s}$. 


\subsection{Quantitative Real-Time PCR ( $q$ RT-PCR)}

qRT-PCR was conducted on a Bio-Rad CFX96 real-time system (Bio-Rad Laboratories, Hercules, CA, USA) using SYBR Premix Ex Taq II (Tli RNase Plus) in Hard-Shell 96-well PCR plates (HSP9655, Bio-Rad, Bio-Rad Laboratories, Hercules, CA, USA) covered with Microseal ' $\mathrm{B}^{\prime}$ adhesive seals (MSB1001). Beta-actin was used as an endogenous control to normalize the expression of target genes and to correct for sample-to-sample variation. Gene-specific primers were designed using Primer-BLAST (https://www.ncbi.nlm.nih.gov/tools/primer-blast) for qRT-PCR and are listed in Table 2. OligoCalc (oligonucleotide properties calculator; http://biotools.nubic.northwestern.edu/OligoCalc.html) was used to analyze the properties of all the primers in the experiment. The amplification efficiencies of the target and reference genes were assessed using gradient dilution templates [30]. qRT-PCR was performed in $25 \mu \mathrm{L}$ reactions under the following two-step PCR amplification conditions (standard procedure): denaturation at $95^{\circ} \mathrm{C}$ for $30 \mathrm{~s}$, followed by 40 cycles of $95^{\circ} \mathrm{C}$ for $10 \mathrm{~s}$ and $60^{\circ} \mathrm{C}$ for $30 \mathrm{~s}$. Finally, melting curve analysis was performed. To test the reproducibility of the data, three biological replicates and three technical replicates were examined. The negative controls were treated with $\mathrm{ddH}_{2} \mathrm{O}$ instead of DNA for the non-template reaction. Relative expression levels were determined using the comparative $2^{-\Delta \Delta C t}$ method for relative quantification [31]. The significant differences between samples were determined by DPS (data processing system) software v9.5 with one-way analysis of variance (ANOVA) and Tukey's post-hoc test [32]. The level of significance was set at $p<$ 0.05. All experimental results were presented using GraphPad Prism 5.

Table 2. Primers used in this study.

\begin{tabular}{|c|c|c|c|}
\hline Primer Name & Forward $\left(5^{\prime}-3^{\prime}\right)$ & Reverse $\left(5^{\prime}-3^{\prime}\right)$ & Product Length (bp) \\
\hline \multicolumn{4}{|c|}{ For prokaryotic expression } \\
\hline SzeaOBP1 & $\frac{\text { CGGGATCCGGAACAAACGA }}{\text { CСCCCAA (BamH1) }}$ & $\begin{array}{l}\text { CGCTCGAGAAGATTGTGGTCC } \\
\text { TCTTTAA }(\text { Xhol) }\end{array}$ & 345 \\
\hline SzeaOBP28 & $\begin{array}{l}\text { CGGGATCCATGTTTGACGAAT } \\
\text { CCACATT (BamH1) }\end{array}$ & $\begin{array}{l}\text { CGCTCGAGAACCATCATATAG } \\
\text { GCTTCTG }(\mathrm{Xhol})\end{array}$ & 372 \\
\hline \multicolumn{4}{|c|}{ For qRT-PCR } \\
\hline SzeaOBP1 & CGACTCСТTCTACСАССАС & AACACTGAACCGCATCTC & 206 \\
\hline SzeaOBP28 & AATCAAAGTGGAGCAA & TCAAAGCGTCAGGAAT & 175 \\
\hline$\beta$-actin & GGGGCGAATACTGTGAGAAA & AGCAGGTTCAAAAGGCTCAA & 192 \\
\hline
\end{tabular}

\subsection{Sequence Analysis and Phylogenetic Tree Construction}

Sequence information for these two SzeaOBPs was obtained previously from the S. zeamais transcriptome database with National Center for Biotechnology Information (NCBI) accession numbers MK341130 and MK341157. Signal peptides were predicted using Signal P (http://www.cbs.dtu.dk/ services/SignalP/) [33]. Multiple sequence alignment was performed using DNAMAN software. OBP sequences were searched against the NCBI database by running the BLAST program. The results were downloaded as comparable fasta files. Then, on the basis of the sequences, we aligned the OBP family sequences and chose the typical order in insects for comparison by the maximum likelihood (ML) method with 1000 bootstrap replicates in MEGA 7.0 software [34].

\subsection{Cloning of SzeaOBPs and Construction of the Expression Vector}

Sequence information for these two SzeaOBPs were obtained previously from the S. zeamais transcriptome database with NCBI accession numbers MK341130 and MK341157. Gene-specific primers were designed to clone the genes but remove the signal peptide sequences. Both clones were designed to include the BamH1 and Xhol restriction sites. SzeaOBP1 was cloned into the pET-28a expression vector, and SzeaOBP28 was cloned into the pET-32a expression vector. The PCR protocol was as follows: initial denaturation at $98^{\circ} \mathrm{C}$ for $30 \mathrm{~s}$, followed by 40 cycles of $98^{\circ} \mathrm{C}$ for $10 \mathrm{~s}, 58{ }^{\circ} \mathrm{C}$ for $15 \mathrm{~s}$ (pET-SzeaOBP1) or $57^{\circ} \mathrm{C}$ for $15 \mathrm{~s}$ (pET-SzeaOBP28), and $72{ }^{\circ} \mathrm{C}$ for $30 \mathrm{~s}$, and a final extension at $72{ }^{\circ} \mathrm{C}$ for $5 \mathrm{~min}$. Samples were stored at $4{ }^{\circ} \mathrm{C}$ until use. The PCR products and expression vectors 
were separately digested with the same restriction enzymes-BamH1 and Xhol—to complete the double enzymatic digestion. The $50 \mu \mathrm{L}$ digestion reactions were prepared as follows: PCR product or expression vector $(30 \mu \mathrm{L})$, FastDigest Green buffer $(5 \mu \mathrm{L})$, enzyme $1(2 \mu \mathrm{L})$, enzyme $2(2 \mu \mathrm{L})$, ddH $\mathrm{H}_{2} \mathrm{O}$ $(11 \mu \mathrm{L})$. The reaction solution was mixed evenly after gentle centrifugation and kept at $37^{\circ} \mathrm{C}$ for 2-4 h. The target gene fragment was inserted into the expression vector to construct a recombinant prokaryotic expression vector containing the target gene sequence. Ligation was performed with $\mathrm{T} 4$ DNA ligase (Thermo Fisher Scientific, Waltham, MA, USA) in $25 \mu \mathrm{L}$ reactions, which were kept at $22^{\circ} \mathrm{C}$ for $2-4 \mathrm{~h}$ for completion of the reaction. The amplification products were purified by gel recovery with the MiniBEST Agarose Gel DNA Extraction Kit Ver.4.0 (TaKaRa, Dalian, China). Positive clones were sequenced by General Biosystems (Anhui, China). After sequencing inoculate $3 \mathrm{~mL}$ bacterial solution to $300 \mathrm{~mL}$ LB medium containing corresponding antibiotics, the correct bacterial clones were cultured in large volumes, and recombinant plasmid extraction was carried out using a plasmid extraction kit (Axygen, Union City, CA, USA). Finally, the plasmids were transformed into Escherichia coli (E. coli) BL21 derivative Rosetta (DE3) competent cells.

\subsection{Prokaryotic Expression and Purification of the Recombinant pET-SzeaOBP Proteins}

Expression of the recombinant SzeaOBP proteins was induced. First, expression was induced in a small culture. Two single colonies harboring pET-SzeaOBP1 or pET-SzeaOBP28 were selected and inoculated in $5 \mathrm{~mL}$ of LB liquid medium (cells containing pET-SzeaOBP1 were cultivated in medium containing $100 \mu \mathrm{g} / \mathrm{mL}$ ampicillin, and cells containing pET-SzeaOBP28 were cultivated in medium containing $50 \mu \mathrm{g} / \mathrm{mL}$ kanamycin sulfate) (Solarbio, Beijing, China); the cells were cultured overnight with shaking at $37^{\circ} \mathrm{C}$. Expression was induced in the experimental group by addition of isopropyl-beta-D-thiogalactopryranoside (IPTG) (Solarbio, Beijing, China) at a final concentration of $1 \mathrm{mM}$, and the cells were grown at $37^{\circ} \mathrm{C}$ for an additional $4 \mathrm{~h}$; expression was not induced in the control cells. The samples were centrifuged at 12,000 rpm for $10 \mathrm{~min}$, and the supernatant was discarded. The bacterial cell pellet was lysed as follows: 20-30 $\mu \mathrm{L}$ of 5× loading buffer was added, and the suspensions were boiled for $10 \mathrm{~min}$. Then, $10 \mu \mathrm{L}$ samples were obtained for sodium dodecyl sulfate polyacrylamide gel electrophoresis (SDS-PAGE) analysis. Then, large-scale induction was performed. A total of $3 \mathrm{~mL}$ of bacterial culture was used to inoculate $300 \mathrm{~mL}$ of LB medium containing the corresponding antibiotics, and induction of expression was conducted in large quantities. The cells were lysed by ultrasonication as follows: the induced $300 \mathrm{~mL}$ cultures were centrifuged at $5000 \mathrm{rpm}$ for $10 \mathrm{~min}$, and bacterial pellets were obtained (approximately 1.2 2 $\mathrm{g}$ (wet weight) of bacteria was obtained by centrifugation of each $300 \mathrm{~mL}$ bacterial culture). The bacteria were resuspended in $10 \mathrm{~mL}$ of $0.01 \mathrm{M}$ phosphate buffer saline (PBS) $(\mathrm{pH}=7.4)$. Then, the bacteria were ultrasonicated at $100 \mathrm{~W}$ in an ice bath for $16 \mathrm{~min}$ and kept at $4{ }^{\circ} \mathrm{C}$. Following from this, the cells were centrifuged at $5000 \mathrm{rpm}$ for $10 \mathrm{~min}$ to obtain the precipitate and supernatant, and $20 \mu \mathrm{L}$ of the supernatant sample was subjected to SDS-PAGE. The precipitate was resuspended in an $8 \mathrm{M}$ urea solution containing of $10 \mathrm{~mL}$ of imidazole and ultrasonicated at $100 \mathrm{~W}$ for $10 \mathrm{~min}$ in an ice-water bath, and $20 \mu \mathrm{L}$ of the sample was retained for electrophoresis. The samples were centrifuged at $5000 \mathrm{rpm}$ and $4{ }^{\circ} \mathrm{C}$ for $15 \mathrm{~min}$, and the supernatant was collected. Purification of the His-tagged proteins was performed by affinity column chromatography using Ni-NTA resin. The purification buffer used contained urea $(8 \mathrm{M})$ and PBS (pH 7.8). The eluents were 30 and $300 \mathrm{mM}$ imidazole in PBS (pH 7.8). First, the recombinant protein present in the supernatant was purified by Ni column chromatography. The eluent was placed in a dialysis bag, and dialysis was carried out with $1 \times$ PBS for completion of the purification of the supernatant.

Next, the recombinant protein present in the precipitate was purified by Ni column chromatography and placed in a dialysis bag. The protein was renatured by applying a urea buffer gradient $(6,4$, $3,2,1$, and $0 \mathrm{M}$ ) for $2 \mathrm{~h}$ at $4{ }^{\circ} \mathrm{C}$. Dialysis was performed for completion of the purification of the precipitate. The dialysis buffer was formulated as follows: 5\% glycerol, $1 \%$ L-arginine, $2 \%$ glycine, and urea, dissolved in $1 \times$ PBS solution. Finally, the recombinant protein samples were quantified as previously described. 


\subsection{Preparation of Multi-Clonal Antibody and Western Blot Analysis}

New Zealand white rabbits were immunized four times with the recombinant purified protein. The whole blood was collected and detected by ELISA. The results were qualified and the antibodies were stored at $-80{ }^{\circ} \mathrm{C}$ for reserve. All the samples were prepared and quantified using the Total Protein Extraction Kit (Thermo, Waltham, MA, USA) and then quantified using the BCA Protein Assay Kit (Thermo, Waltham, MA, USA). SDS-PAGE analysis was performed with an $8 \%-12 \%$ separating gel and $5 \%$ concentrating gel, with $60 \mu \mathrm{g}$ of total protein sample per pore at $10-15 \mu \mathrm{L}$ per pore. The concentrating gel was run at $60 \mathrm{~V}$, and the separating gel was run at $80 \mathrm{~V}$; electrophoresis was performed for approximately $2 \mathrm{~h}$. A PVDF membrane (Millipore, Shanghai, China) was soaked in methanol for $20 \mathrm{~s}$ and then transferred to Tris-glycine transfer buffer (containing 5\% methanol) for at least $5 \mathrm{~min}$. The SDS-PAGE gel was equilibrated for at least $30 \mathrm{~min}$ in Tris-glycine transfer buffer. Under cooling conditions, $100 \mathrm{~V}$ was applied to transfer the proteins to the membrane for $2 \mathrm{~h}$ at constant voltage and constant humidity. Then, the transfer film was sealed. After the transfer process was completed, the transfer film was placed in T-TBS (containing 5\% skimmed milk powder or BSA). The transfer film was sealed at room temperature for $1 \mathrm{~h}$ and then rinsed three times with T-TBS for 5 min. Primary antibody (Huabio, Hangzhou, China) and secondary antibody hybridization followed by primary antibody blocking were performed in T-TBS (containing 3\% skimmed milk powder or BSA) at a specific proportion, and the transfer film was incubated overnight at $4{ }^{\circ} \mathrm{C}$. Then, the transfer film was rinsed four times in T-TBS for $5 \mathrm{~min}$. The secondary antibody was dissolved in T-TBS (containing $2 \%$ skimmed milk powder) and incubated with the transfer film at room temperature for $1 \mathrm{~h}$. Then, the transfer film was rinsed five times in T-TBS for $5 \mathrm{~min}$. Afterwards, for signal detection, SuperSignal West Dura Extended Duration Substrate (Thermo Pierce, Wilmington, DE, USA) was used to prepare $1 \mathrm{~mL}$ of ECL (GE, Fairfield, CT, USA) working fluid according to the manufacturer's instructions. The transfer film was incubated with the working fluid at room temperature for $1 \mathrm{~min}$, and then the excess ECL reagent was removed, and the transfer film was sealed with X-ray film (Hua Dong Medicine, Shanghai, China) in a dark box for exposure for 5-10 min before fixing and developing.

\subsection{Fluorescence Competitive Binding Assays}

Emission fluorescence spectra were recorded on a Fluoromax-4500 fluorescence spectrophotometer (Hitachi, Tokyo, Japan) at room temperature in right-angle configuration, with a $1 \mathrm{~cm}$ light-path quartz cuvette and $5 \mathrm{~nm}$ slits for both excitation and emission. The protein was dissolved in $50 \mathrm{mM}$ Tris- $\mathrm{HCl}$ buffer ( $\mathrm{pH}$ 7.4), and ligands were added as $1 \mathrm{mM}$ methanol solutions. A methanol solution of N-Phenyl-1-naphthylamine (1-NPN) (1 mM) was used as the fluorescent probe, and chromatography-grade methanol was used as the solvent. For determination of the binding constants of the SzeaOBPs with the probe, the excitation wavelength was set at $337 \mathrm{~nm}$, and the emission wavelength was increased from 370 to $500 \mathrm{~nm}$ for scanning. The target SzeaOBP proteins were diluted in Tris- $\mathrm{HCl}$ buffer ( $\mathrm{pH} 7.4$ ) to a final concentration of $2 \mu \mathrm{M}$. After the sample was added, the fluorescence intensity was allowed to stabilize (approximately $15 \mathrm{~s}$ ), and the maximum fluorescence intensity was recorded; the binding constant between the protein and probe was determined. This process was repeated three times for each sample. Then, the ligands (odorant standard samples) were diluted with pure methanol for competitive binding analysis. The final concentration of each ligand was $1 \mathrm{M}$. The final concentration of ligands in the colorimetric dish increased by $2 \mu \mathrm{M}$ upon adding the ligands one by one. The fluorescence intensity was recorded from 2 to $16 \mu \mathrm{M}$. The binding constants between the target SzeaOBP proteins and the ligands were determined. The fluorescence intensity was measured by adding $50 \mathrm{mM}$ Tris- $\mathrm{HCl}$ buffer, SzeaOBP protein, and the fluorescence probe 1-NPN to the colorimetric dish for fluorescence measurement. The final concentration was $2 \mu \mathrm{M}$. When the fluorescence intensity was stable, the maximum fluorescence intensity was recorded, and then the ligands dissolved in methanol were added to the colorimetric dish one by one. The concentration increased from $2 \mu \mathrm{M}$, and the changes in fluorescence intensity were recorded. Each measurement was repeated three times. 
To calculate the binding constants, the fluorescence intensity and ligand concentration were plotted using GraphPad Prism 5. Assuming that 1-NPN binds to the protein at a 1:1 ratio and that the protein was $100 \%$ active, the curve was linearized using a Scatchard plot. IC $_{50}$ (ligand concentration at which the fluorescence intensity of the complex decreases by half) values were used to calculate the dissociation constants of the SzeaOBPs and the ligands by the following equation: $\mathrm{Ki}=\left[\mathrm{IC}_{50}\right] /\left(1+[1-\mathrm{NPN}] / \mathrm{K}_{1-\mathrm{NPN}}\right)$, where $[1-\mathrm{NPN}]$ is the concentration of the unconjugated ligand, and $\mathrm{K}_{1-\mathrm{NPN}}$ represents the dissociation constants of the SzeaOBPs and 1-NPN.

\subsection{Behavioural Experiments Using a Y-Tube Olfactometer}

The behavioral experiments were designed to test the results for selected odorants. The odorant compounds used in behavioral experiments are from Table 1. To avoid the effects of temperature and light on the experiment, the evaluations were performed in a constant temperature and humidity (CTH) room at $28 \pm 1{ }^{\circ} \mathrm{C}$ and $80 \%$ relative humidity under dim light supplied by a red fluorescent tube with no natural lighting. A Y-tube olfactometer system that was previously described by Yusuf and Takabayashi $[35,36]$ was used to test the attractiveness of different odorant treatments to adult maize weevils. The system comprised a central tube $(10 \mathrm{~cm}$ long) and two lateral arms (each $15 \mathrm{~cm}$ long and $15 \mathrm{~mm}$ wide). The angles between the two arms were $75^{\circ}$. Each arm was connected to a glass chamber ( $200 \mathrm{~mL}$ capacity) holding the different odorants. The different parts of the device were connected in the following order: air pump, activated carbon filter, distilled water humidifier, odorant source device, gas flow meter, and Y-tube olfactometer. The parts were connected by Teflon tubes. Airflow through both arms was generated by applying air pressure, and the air was purified using a charcoal-filled gas wash bottle. The airflow through the arms of the Y-tube $(150 \mathrm{~mL} / \mathrm{min} / \mathrm{arm})$ was adjusted by using flow metres, which were positioned between the flasks and the Y-tube. A clean Y-tube was used for each test to avoid carryover of odorants.

Before bioassays, according to the experimental requirements, the odorant source was placed in the odorant source device, which was then ventilated for $15 \mathrm{~min}$ so that the odorant filled the tube to ensure accuracy of the test results. The antennae and appendages of the selected insects were verified to be intact, and the insects were confirmed to be active. The insects were introduced from the base of the main arm of the Y-tube olfactometer. The selected odorant was used for the treatment group, and a blank was used for the control group. A single adult S. zeamais insect was introduced into the Y-tube olfactometer at the entrance of the stem, with a maximum observation duration of $10 \mathrm{~min}$ per beetle, and the responses were considered positive when the insects reached at least $2 \mathrm{~cm}$ along the arm connected to the test chambers. The lack of a positive response was recorded if an insect did not reach $2 \mathrm{~cm}$ after $10 \mathrm{~min}$ of observation. Insects were used only once and then discarded. Each odorant was used to test 30 adult maize weevils, and the number of male and female insects per test was the same. Three groups of experiments were repeated for three times. When calculating results, only the number of insects making the selection was counted, and the insects that did not made a selection were not included.

\subsection{RNA Interference}

Specific primers for SzeaOBP1 were designed to amplify the fragment to synthesize the double strand RNA. The primers were used by adding the T7 sequence polymerase binding during amplification. The primers were as follows: dsSzeaOBP1-F: TAATACGACTCACTATAGGGGGAAC AAACGACCCCCAA; dsSzeaOBP1-R: TAATACGACTCACTATAGGGAAGATTGTGGTCCTCTTTAA. dsGFP-F: TAATACGACTCACTATAGGGAGTGCTTCAGCCGCTACCC; dsGFP-R: TAATACGACT CACTATAGGGGCGCTTCTCGTTGGGGTC. The primers were chosen according to different regions in the qRT-PCR test. The green fluorescent protein was used to compare the control and the negative control (GenBank accession number: KF410615.1). The double-stranded RNA (dsRNA) was synthesized using an HTE Thermo Scientific following the manufacturer's instructions. The purity and integrity of dsRNA was confirmed by $1 \%$ agarose gel electrophoresis. The dsRNA concentration was determined 
by NanoDrop spectrophotometer (Thermo Fisher Scientific, USA), and stored in the RNase-free tube at $-80{ }^{\circ} \mathrm{C}$ until used.

The treatment was fed to the adult insect every $12 \mathrm{~h}$, and we collected the insect after $72 \mathrm{~h}$ treatment. Three treatments were set up for RNA interference (RNAi) consisting of RNase-free water (controls), dsGFP, and dsRNA group. Thirty $S$. zeamais adults in each group were used for the interference assays with the dose of $3 \mu \mathrm{g}$, and were repeated three times. The efficiency of the RNA interference was verified using qRT-PCR by extracting the total RNA from each group. The behavior responses of different treatments were assessed in a Y-tube olfactometer.

\section{Results}

\subsection{Comparison of Relative mRNA Expression}

Total RNA samples of high quality and purity were obtained, and cDNA, which was obtained by reverse transcription, was used as the template for qRT-PCR. Insects at six different developmental stages, including LL (low-instar larva), HL (high-instar larva), pupae (prepupa and postpupa), EA (eclosion adult), MA (male adult), and FA (female adult) exhibited different levels of SzeaOBP1 and SzeaOBP28, as shown in Figure 1. The SzeaOBP1 levels in the LL samples were statistically significant. The expression level of SzeaOBP1 was highest in the LL stage. The next highest levels were observed for the HL, EA, and FA stages. Compared with other stages, the expression levels in the pupae and MA were the lowest. This finding may indicate that the SzeaOBP1 levels are highest during the early larval stage, decreasing gradually with development. The expression of SzeaOBP28 was highest in the EA, MA, and FA stages, followed by pupae, and the lowest levels were observed in the LL and ML stages. In general, the expression level was low at the early stage of development and high at the EA and adult stages.

SzeaOBP1

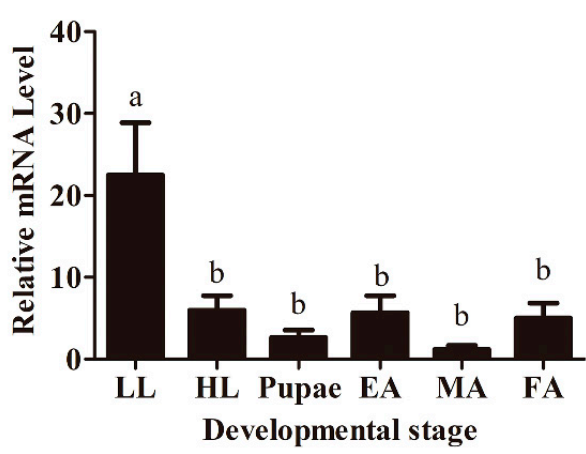

SzeaOBP28

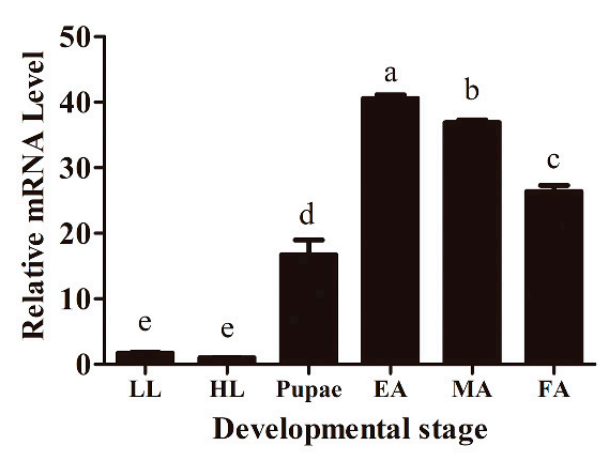

Figure 1. Relative mRNA levels. Expression patterns of various Sitophilus zeamais odorant-binding protein (OBP) genes in different developmental stages, including LL (low-instar larva), HL (high-instar larva), pupae (prepupa and postpupa), EA (eclosion adult), MA (male adult), and FA (female adult). The gene expression levels in the various tissues were normalized relative to the expression in different tissues. The data are presented as the means of three replicates $(n=3) \pm$ SE. Different lowercase letters indicate significant differences $(p<0.05)$.

\subsection{SzeaOBP Sequence Alignment and Phylogenetic Analysis}

The SzeaOBP1 sequence consisted of $417 \mathrm{bp}$, and the SzeaOBP28 sequences consisted of $432 \mathrm{bp}$, encoding 138 and 143 amino acids, respectively. The initial 23 and 19 amino acid residues of SzeaOBP1 and SzeaOBP28, respectively, were predicted to constitute the signal peptides. Sequence alignment of SzeaOBP1 with DponOBP5 and DarmOBP5 showed similar sequence identity (identity $>55.40 \%$ ), whereas sequence alignment of SzeaOBP28 with RferOBP10 and RferOBP107 had high homology (identity $>79.72 \%$ ). SzeaOBP1 had only four conserved cysteine residues, exhibiting loss of two conserved cysteines, suggesting that this protein belonged to the Minus-C OBP subfamily of 
proteins. Sequence alignment showed that SzeaOBP28 possessed a typical six-cysteine motif, that is, $C_{1}-X_{27}-C_{2}-X_{3}-C_{3}-X_{37}-C_{4}-X_{10}-C_{5}-X_{8}-C_{6}$, where $X$ is any amino acid. SzeaOBP28 belonged to the classic OBP subfamily of proteins (Figure 2). An ML phylogenetic tree was constructed using the sequences of SzeaOBP1, SzeaOBP28, and 30 OBPs from eight Coleoptera insects. Minus-C OBPs and classic OBPs formed two branches: Minus-C OBPs were clustered with SzeaOBP1, and classic OBPs were clustered with SzeaOBP28. SzeaOBP1 was clustered with DponOBP5, and DarmOBP5, SzeaOBP28, RferOBP10, and RferOBP107 were clustered together, indicating that these genes have slow evolution rates and are highly conserved, which is consistent with the results of multiple sequence alignment (Figure 3).
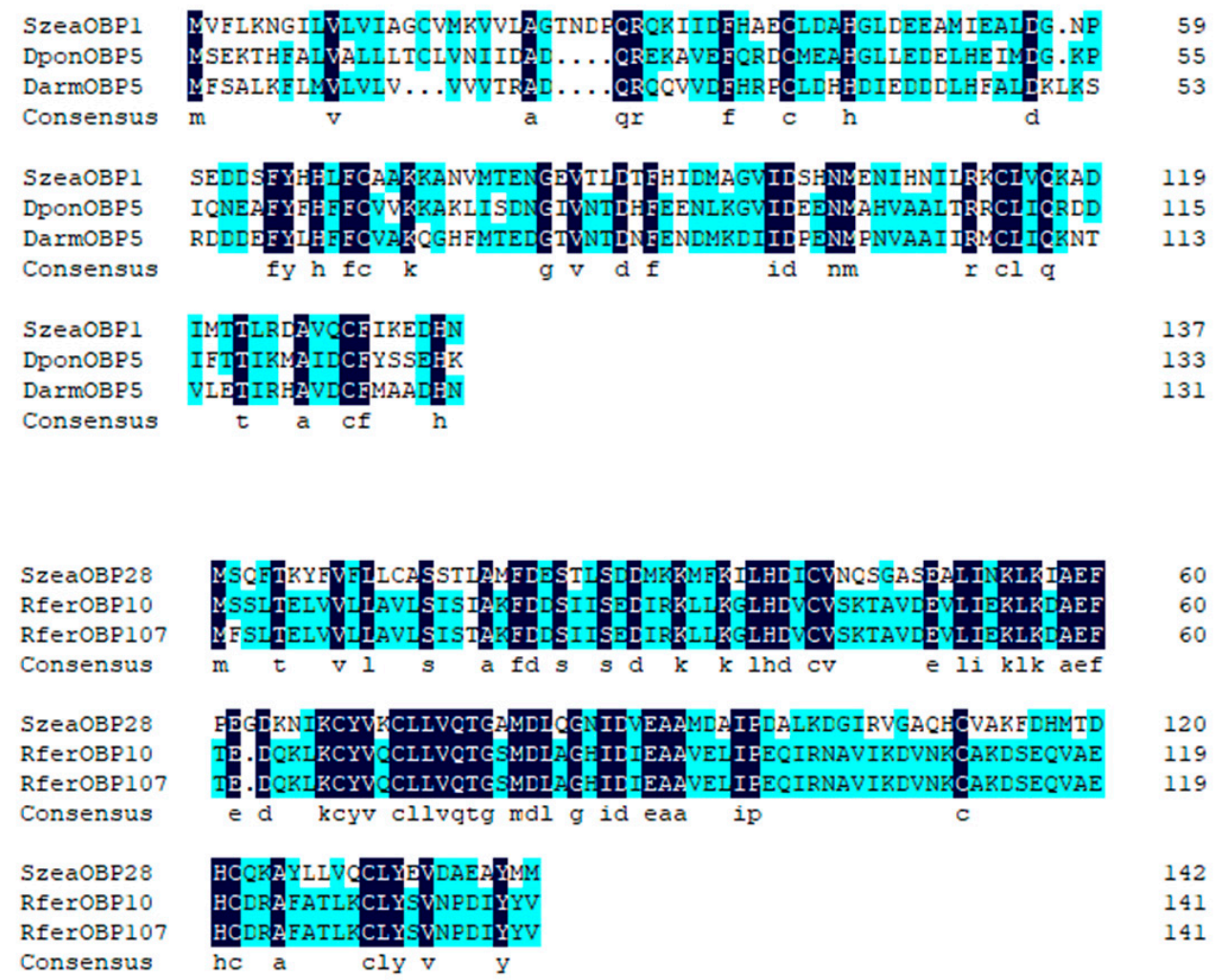

Figure 2. Multiple sequence alignment of OBPs from Sitophilus zeamais and other Coleoptera insects. The species names and GenBank accession numbers of the four OBPs are as follows: Dendroctonus ponderosae (DponOBP5, AKK25133.1); Dendroctonus armandi (DarmOBP5, ALM64967.1); Rhynchophorus ferrugineus (RferOBP10, ANE37554.1; RferOBP107, AVR54529.1). 


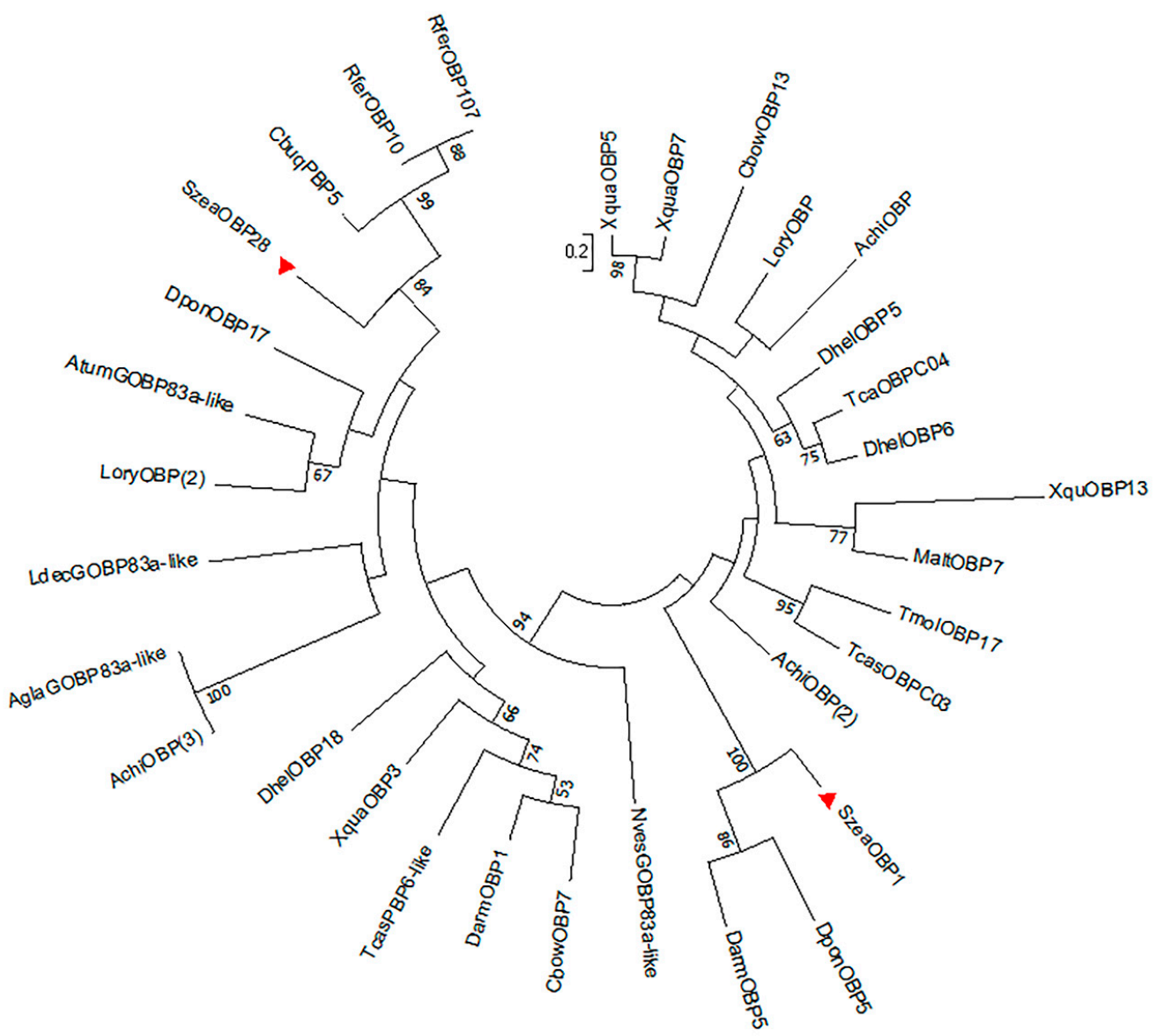

Figure 3. Maximum likelihood tree of 32 OBPs from Sitophilus zeamais and other Coleopteran insects with 1000 bootstrap replicates. The species names and GenBank accession numbers for all the OBP sequences as follows: Aethina tumida (AtumGOBP83a-like, XP_019868892.1); Anoplophora chinensis (AchiOBP, AUF72980.1; AchiOBP, AUF72977.1; AchiOBP, AUF72991.1); Anoplophora glabripennis (AglaGOBP83a-like, XP_023310142.1); Colaphellus bowringi (CbowOBP7, ALR72495.1; CbowOBP13, ALR72501.1); Cyrtotrachelus buqueti (CbuqPBP5, APG79366.1); Dastarcus helophoroides (DhelOBP5, AIX97051.1; DhelOBP6, AIX97052.1; DhelOBP18, AIX97064.1); Dendroctonus armandi (DarmOBP1, AIY61044.1; DarmOBP5, ALM64967.1); Dendroctonus ponderosae (DponOBP5, AKK25133.1; DponOBP17, AKK25141.1); Leptinotarsa decemlineata (LdecGOBP83a-like, XP_023019484.1); Lissorhoptrus oryzophilus (LoryOBP, AHE13799.1; LoryOBP, AHE13800.1); Monochamus alternatus (MaltOBP7, AIX97022.1); Nicrophorus vespilloides (NvesGOBP83a-like, XP_017781594.1); Rhynchophorus ferrugineus (RferOBP10, ANE37554.1; RferOBP107, AVR54529.1); Tenebrio molitor (TmolOBP17, AJM71491.1); Tribolium castaneum (TcasOBPC03, EFA07546.1; TcasOBPC04, EFA07430.1; TcasPBP6-like, XP_015835846.1); Xylotrechus quadripes (XquaOBP3, AXO78381.1; XquaOBP5, AXO78383.1; XquaOBP7, AXO78385.1; XquaOBP13, AXO78391.1)

\subsection{Cloning Results and Bacterial Expression}

SzeaOBP1 and SzeaOBP28 were successfully amplified, and cohesive ends were generated by PCR for ligation with the expression vector. After verification of the fragments encoding the recombinant protein by sequencing, the target sequence, after removal of the signal peptide-encoding sequence, was successfully cloned into pET-28a for SzeaOBP1 and pET-32a for SzeaOBP28. The encoded SzeaOBP1 protein was His-tagged; the predicted molecular weight was approximately $19 \mathrm{kDa}$. The encoded SzeaOBP28 protein was His-tagged and Trx-tagged; the predicted molecular weight was approximately $32 \mathrm{kDa}$. SDS-PAGE was performed $4 \mathrm{~h}$ after induction with $1 \mathrm{mM} \mathrm{IPTG}$ at $37^{\circ} \mathrm{C}$, and distinct bands were observed at the expected size of $19 \mathrm{kDa}$. After purified by column chromatography, bands corresponding to SzeaOBP1 (at $19 \mathrm{kDa}$ ) were present in the supernatant and precipitate, which indicated 
that this protein was expressed in both the supernatant and inclusion bodies. Bands corresponding to SzeaOBP28 $(32 \mathrm{kDa})$ were present in the precipitate, indicating that this protein was expressed in inclusion bodies.

After elution with 30 and $300 \mathrm{mM}$ imidazole, distinct bands for SzeaOBP1 were observed at the expected size of $19 \mathrm{kDa}$. After elution with $300 \mathrm{mM}$ imidazole, SzeaOBP28 exhibited distinct bands at the expected size of $32 \mathrm{kDa}$. Protein dialysis and quantitative results showed that there were distinct bands corresponding to SzeaOBP1 at $19 \mathrm{kDa}$ and SzeaOBP28 at $32 \mathrm{kDa}$ (Figure 4). The isoelectric points of SzeaOBP1 and SzeaOBP28 were 4.95 and 4.92, respectively.
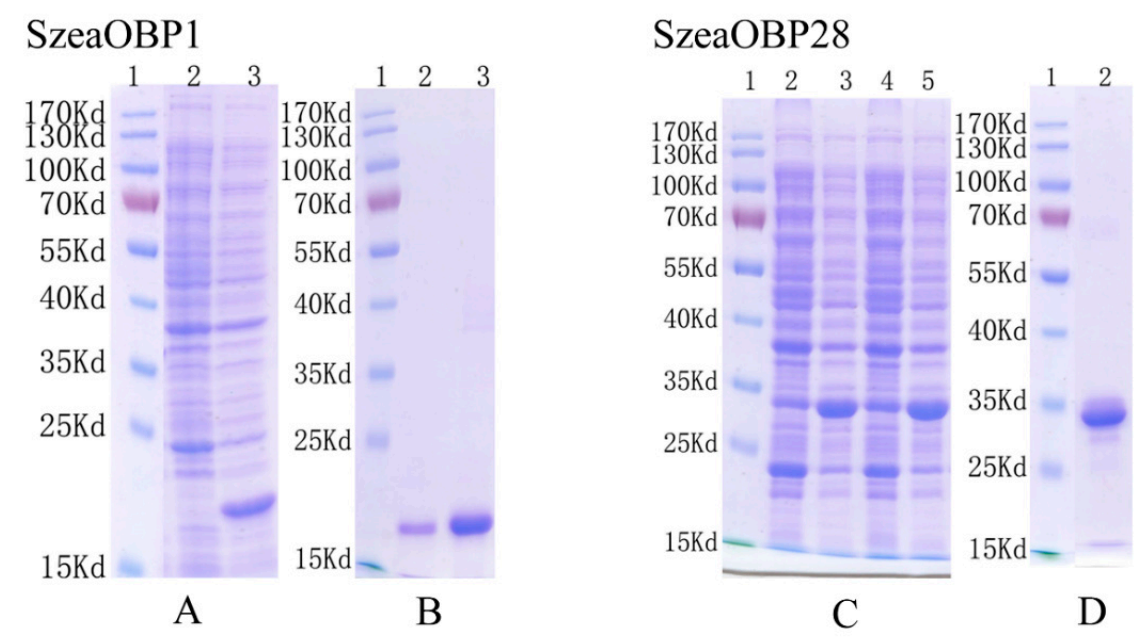

Figure 4. SDS-PAGE and western blot analysis of the expressed products and purified pET-SzeaOBPs. $(\mathrm{A}, \mathrm{C})$ show the $\mathrm{pET}-\mathrm{SzeaOBP}$ recombinant protein that was primarily expressed by induction with isopropyl-beta-D-thiogalactopryranoside (IPTG) and detected by SDS-PAGE. (B,D) show western blot analyses of the purified SzeaOBPs. Lane 1 in all the images shows the protein molecular weight marker. (A) lane 2: SzeaOBP1-transformed Escherichia coli, not induced; lane 3: SzeaOBP1-transformed Escherichia coli, induced. (B) lane 2 and 3: recombinant purified SzeaOBP1 protein. (C) lanes 2 and 4: SzeaOBP28-transformed Escherichia coli, not induced; lanes 3 and 5: SzeaOBP28-transformed Escherichia coli, induced. (D) lane 2: recombinant purified SzeaOBP28 protein.

\subsection{Antibody Production and Western Blot Analysis of the Two Recombinant Proteins}

The effect of rabbit serum was evaluated and detected on the basis of OD values at different dilution ratios. The OD $450 \mathrm{~nm}$ of SzeaOBP1 at a ratio of 1:64,000 was 1.895, and the OD $450 \mathrm{~nm}$ of SzeaOBP28 at a ratio of 1:64,000 was 2.342 . The values were all greater than 0.6 , which was indicative of good quality. Total protein was extracted from S. zeamais at six different developmental stages. The total protein concentrations obtained for the LL, HL, pupae, EA, MA, and FA stages were 2108.3 $\mu \mathrm{g} / \mathrm{mL}, 1705.6 \mu \mathrm{g} / \mathrm{mL}, 2486.8 \mu \mathrm{g} / \mathrm{mL}, 1605.38 \mu \mathrm{g} / \mathrm{mL}, 2258.5 \mu \mathrm{g} / \mathrm{mL}$, and $1699.6 \mu \mathrm{g} / \mathrm{mL}$, respectively. The western blot (WB) analysis showed that SzeaOBP1 was highly expressed at the LL, HL, pupae, and EA stages but expressed at low levels at the MA and FA stages. The expression level of SzeaOBP28 was highest at the EA and MA stages, followed by the pupae and FA stages, and the lowest levels were observed at the LL and HL stages (Figure 5). 

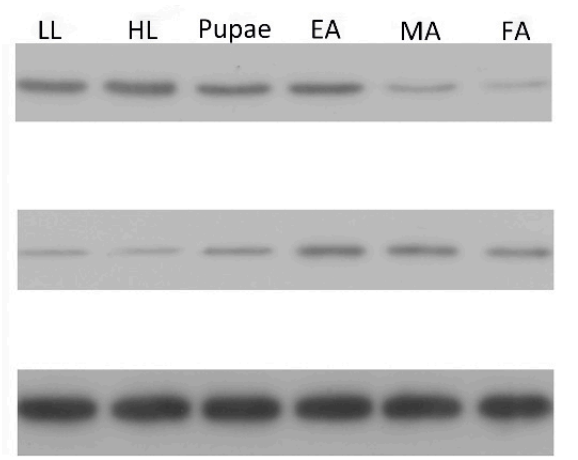

SzeaOBP1

SzeaOBP28

GAPDH

Figure 5. Protein expression patterns of the two proteins in different developmental stages. Detection of expression levels in different development stages of Sitophilus zeamais, including LL (low-instar larva, HL (high-instar larva), pupae (prepupa and postpupa), EA (eclosion adult), MA (male adult), and FA (female adult). The protein molecular weight marker is shown on the left. GAPDH was the control.

\subsection{Fluorescence Competitive Binding Assays}

Upon excitation at $337 \mathrm{~nm}$, the intrinsic fluorescence intensity was low with only Tris buffer and 1 -NPN added, with a value of only $337.16 \pm 3.9$. However, in the presence of recombinant proteins, the spectrum shifted from $470 \mathrm{~nm}$ to approximately $418 \mathrm{~nm}$, accompanied by a sharp increase in fluorescence intensity. The fluorescence values for SzeaOBP1 and SzeaOBP28 reached 1938.33 \pm 72 and $2511.33 \pm 85$, respectively. This finding indicates that the fluorescence probe 1-NPN is suitable for studying the binding of ligands to the two SzeaOBPs. The binding curve for the fluorescent probe 1-NPN with SzeaOBPs is shown in Figure 6.

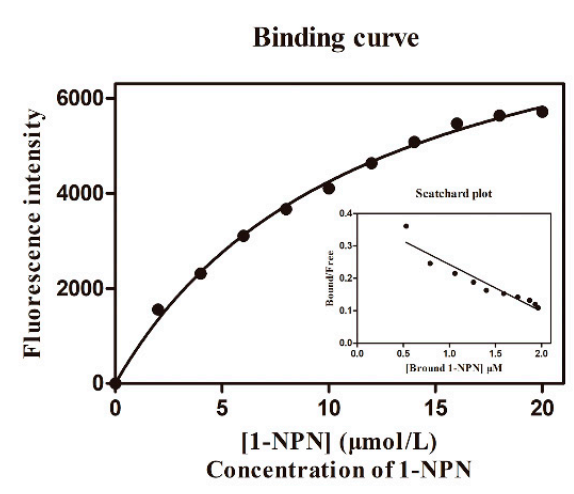

SzeaOBP1

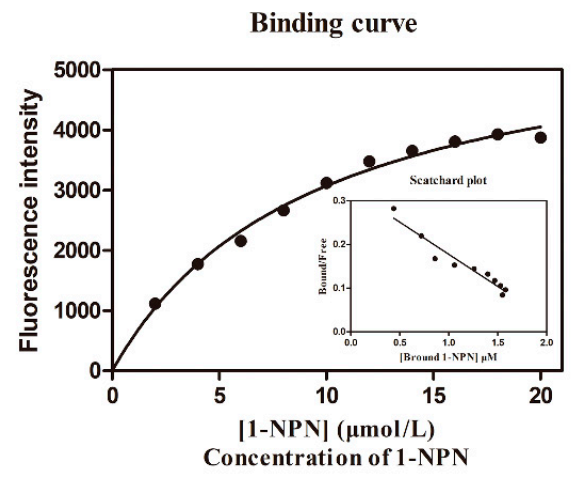

SzeaOBP28

Figure 6. Binding curves and Scatchard plots of the fluorescence probe 1-NPN with SzeaOBP1 and SzeaOBP28. The binding curves and corresponding Scatchard plots indicate that the binding constant of the SzeaOBP1/1-NPN complex was $8.590 \mu \mathrm{M}$, and that of the SzeaOBP28/1-NPN complex was $7.214 \mu \mathrm{M}$.

The $\mathrm{K}_{1-\mathrm{NPN}}$ dissociation constants of the SzeaOBPs complexes were $8.590 \mu \mathrm{M}$ and $7.214 \mu \mathrm{M}$ for SzeaOBP1 and SzeaOBP28, respectively. Then, the dissociation constants of the SzeaOBPs and ligands were calculated using $\mathrm{K}_{1-\mathrm{NPN}}$ values. SzeaOBP1 was highly specific for the major components of all 27 ligands, exhibiting the strongest affinity for cetanol $(2.748 \pm 0.139 \mu \mathrm{M})$ and the weakest affinity for myrcene $(30.27 \pm 0.798 \mu \mathrm{M})$. SzeaOBP28 exhibited a specific binding spectrum with the minor ligands, showing pronounced binding affinity for 4-hydroxy-3-methoxybenzaldehyde $(20.23 \pm 1.918 \mu \mathrm{M})$. Both recombinant SzeaOBP proteins did not bind to decanal, linoleic acid, $(+)-\alpha$-pinene, or the alkanes. The binding affinities of the 27 ligands to the SzeaOBPs are listed in Table 3 and shown in Figure 7. 

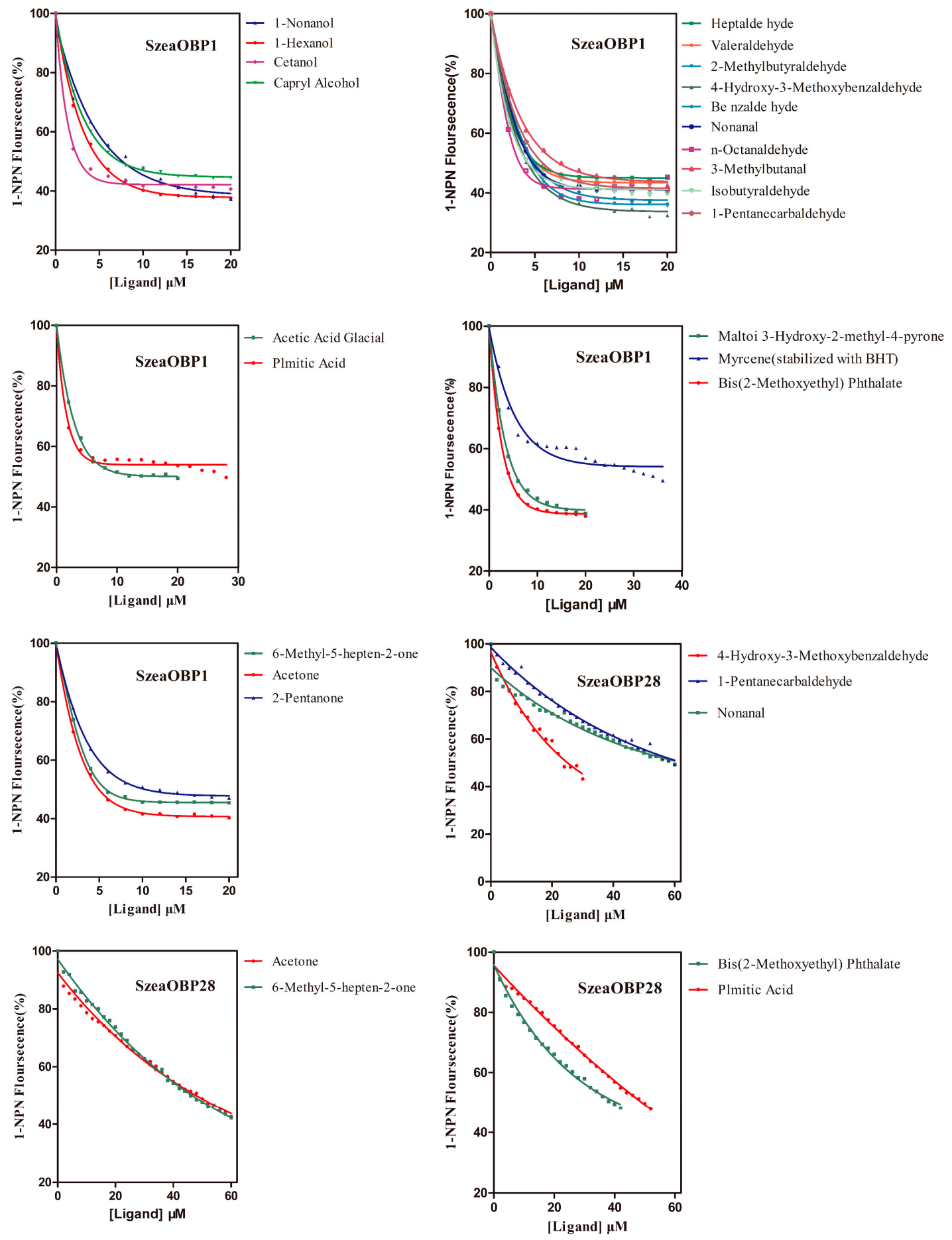

Figure 7. Fluorescence competitive binding curves of the two SzeaOBPs with host plant volatiles. The recombinant proteins and 1-NPN were diluted with $20 \mathrm{mM}$ Tris- $\mathrm{HCl}$ buffer ( $\mathrm{pH}$ 7.4) to a final concentration of $2 \mu \mathrm{M}$. The mixed solution was titrated with each host plant volatile $(1 \mathrm{mM})$ to a final concentration of $0-60 \mu \mathrm{M}$. 
Table 3. Binding affinities of the two SzeaOBPs with 27 tested ligands.

\begin{tabular}{|c|c|c|c|c|}
\hline \multirow{2}{*}{ Ligand } & \multicolumn{2}{|c|}{ SzeaOBP1 } & \multicolumn{2}{|c|}{ SzeaOP28 } \\
\hline & $\mathrm{IC}_{50}(\mu \mathrm{M})$ & $\mathrm{Ki}(\mu \mathrm{M})$ & $\mathrm{IC}_{50}(\mu \mathrm{M})$ & $\mathrm{Ki}(\mu \mathrm{M})$ \\
\hline \multicolumn{5}{|l|}{ Alkanes } \\
\hline Pentadecane & - & - & - & - \\
\hline $\mathrm{N}$-Hexadecane & - & - & - & - \\
\hline \multicolumn{5}{|l|}{ Alcohols } \\
\hline 1-Nonanol & $8.131 \pm 0.274$ & $6.944 \pm 0.234$ & - & - \\
\hline 1-Hexanol & $5.470 \pm 0.186$ & $4.671 \pm 0.159$ & - & - \\
\hline Capryl alcohol & $7.814 \pm 0.233$ & $6.673 \pm 0.199$ & - & - \\
\hline Cetanol & $3.218 \pm 0.162$ & $2.748 \pm 0.139$ & - & - \\
\hline \multicolumn{5}{|l|}{ Aldehyde } \\
\hline Decanal & - & - & - & - \\
\hline Valeraldehyde & $5.715 \pm 0.121$ & $4.880 \pm 0.103$ & - & - \\
\hline Heptaldehyde & $5.707 \pm 0.130$ & $4.874 \pm 0.111$ & - & - \\
\hline $\begin{array}{l}\text { 4-Hydroxy-3- } \\
\text { methoxybenzaldehyde }\end{array}$ & $4.368 \pm 0.203$ & $3.730 \pm 0.173$ & $24.680 \pm 2.340$ & $20.23 \pm 1.918$ \\
\hline 2-Methylbutyraldehyde & $4.916 \pm 0.102$ & $4.198 \pm 0.087$ & - & - \\
\hline Benzaldehyde & $5.198 \pm 0.092$ & $4.439 \pm 0.079$ & - & - \\
\hline Nonanal & $5.179 \pm 0.111$ & $4.423 \pm 0.095$ & $58.855 \pm 1.342$ & $48.242 \pm 1.100$ \\
\hline n-Octanaldehyde & $3.769 \pm 0.120$ & $3.219 \pm 0.103$ & - & - \\
\hline 3-Methylbutanal & $7.617 \pm 0.191$ & $6.505 \pm 0.163$ & - & - \\
\hline Isobutyraldehyde & $4.987 \pm 0.162$ & $4.259 \pm 0.138$ & - & - \\
\hline $\begin{array}{l}\text { 1-Pentanecarbaldehyde } \\
\text { Ketones }\end{array}$ & $6.067 \pm 0.154$ & $5.181 \pm 0.132$ & $59.42 \pm 1.214$ & $48.70 \pm 0.852$ \\
\hline 6-Methyl-5-hepten-2-one & $6.501 \pm 0.150$ & $5.552 \pm 0.128$ & $45.845 \pm 1.232$ & $37.578 \pm 1.010$ \\
\hline Acetone & $5.320 \pm 0.201$ & $4.543 \pm 0.172$ & $48.555 \pm 0.861$ & $39.824 \pm 0.731$ \\
\hline $\begin{array}{l}\text { 2-Pentanone } \\
\text { Acids }\end{array}$ & $11.62 \pm 0.312$ & $9.923 \pm 0.267$ & - & - \\
\hline Palmitic Acid & $28.28 \pm 2.082$ & $24.150 \pm 1.778$ & $49.746 \pm 1.724$ & $40.776 \pm 1.414$ \\
\hline Linoleic acid & - & - & - & - \\
\hline $\begin{array}{c}\text { Acetic acid (glacial) } \\
\text { Others }\end{array}$ & $18.43 \pm 0.840$ & $15.739 \pm 0.717$ & - & - \\
\hline $\begin{array}{l}\text { Maltol (3-hydroxy-2- } \\
\text { methyl-4-pyrone) }\end{array}$ & $6.179 \pm 0.390$ & $5.277 \pm 0.333$ & - & - \\
\hline Myrcene (stabilized with BHT) & $35.45 \pm 0.931$ & $30.27 \pm 0.798$ & - & - \\
\hline Bis(methylglycol) phthalate & $4.762 \pm 0.147$ & $4.067 \pm 0.125$ & $38.865 \pm 0.200$ & $31.857 \pm 0.164$ \\
\hline$(+)$-a-Pinene & - & - & - & - \\
\hline
\end{tabular}

\subsection{Behavioural Response to Host Plant Volatile Components}

According to the experimental results in the previous section, four odorant compounds with strong ability were selected for behavioral experiments. The responses of $S$. zeamais to compounds with strong binding ability from different host plants were determined (Figure 8). Volatiles from the intact host plant grains were selected by comparison of the responses of male and female S. zeamais insects. Of the different standard odorant sample treatments, the 4-hydroxy-3-methoxybenzaldehyde treatment stimulated activity in a significantly higher number of normal male and female weevils than the control treatment. The active normal male and female weevils were strongly attracted to volatiles, with males exhibiting slightly stronger attraction than females. Significant differences in male and female weevils' attraction to volatiles were also found between the 2-methylbutyraldehyde and the cetanol. There was only a slight difference in the response of females and males to the three odorant compounds. The stimulation of n-octanaldehyde had no obvious effect on the female and male of maize weevils. 

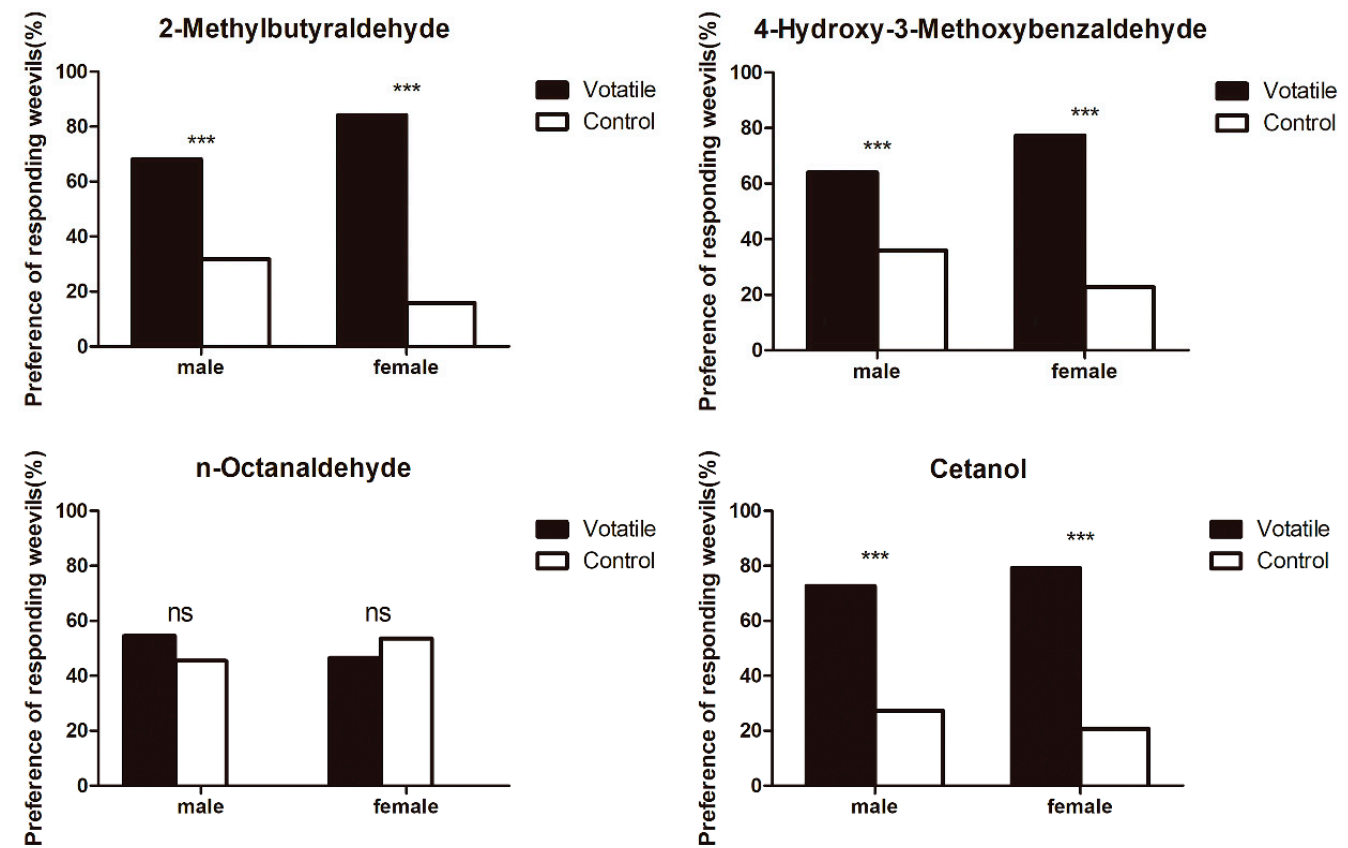

Figure 8. Responses of male and female Sitophilus zeamais adults to volatiles from four host plant combinations in the Y-tube olfactometer assays. Activity is expressed as percentage of weevils responding, and bars followed by different markers indicate significantly different activity of the weevils between the treatments $(p<0.05)$. The mean values shown are predicted values from regression analysis. ' ${ }^{* \prime}$ indicates significant differences from even distribution at ${ }^{*} p<0.05$, or ${ }^{* *} p<0.01,{ }^{* * *} p<0.001$. 'ns' indicates not significantly different.

\subsection{Effect of dsRNA Treatment on Sitophilus Zeamais Behaviour}

After the $72 \mathrm{~h}$ dsRNA feeding treatment with the adult Sitophilus zeamais, qRT-PCR was used to detect the relative reduction of transcript level. The expression was reduced by $80 \%$ with SzeaOBP1 in adults. The attraction to plant volatiles was tested using the Y-tube olfactometer with the same volatiles as before. The OBP1 treatment was significantly different compared with the feeding group. The dsRNA (SzeaOBP1)-fed adults were significantly affected in this experiment. Meanwhile, dsRNA (SzeaOBP1)-treated beetles showed lower attraction to these three volatiles than normal insects, indicating that SzeaOBP1 is important in perception of these odorants (Figures 9 and 10). 


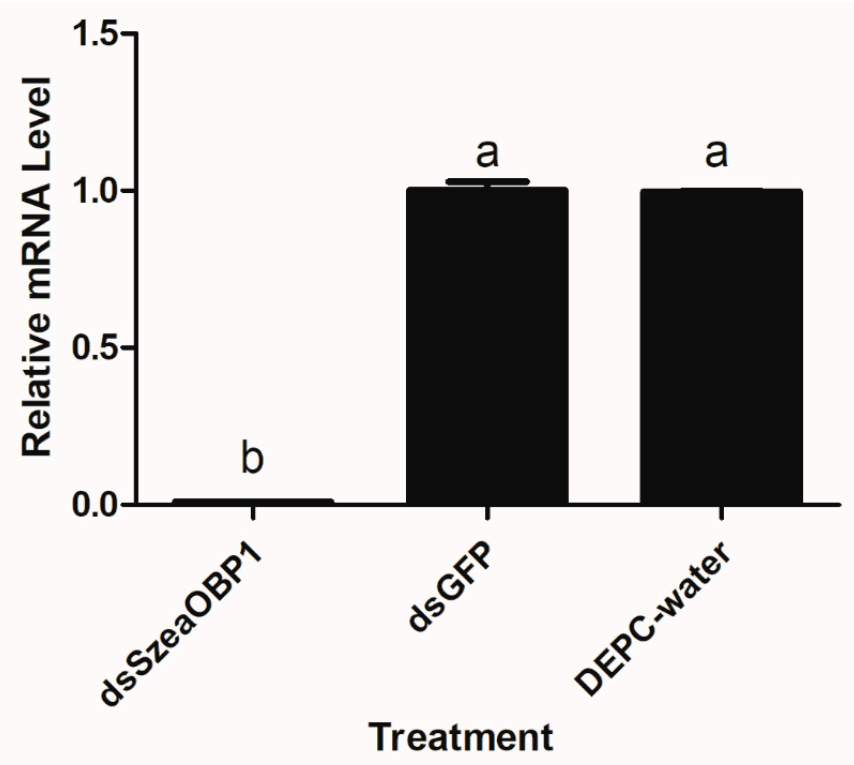

Figure 9. Effect of RNAi treatment on the transcript levels of SzeaOBP1 in adults. DEPC-water and GFP were compared as controls.
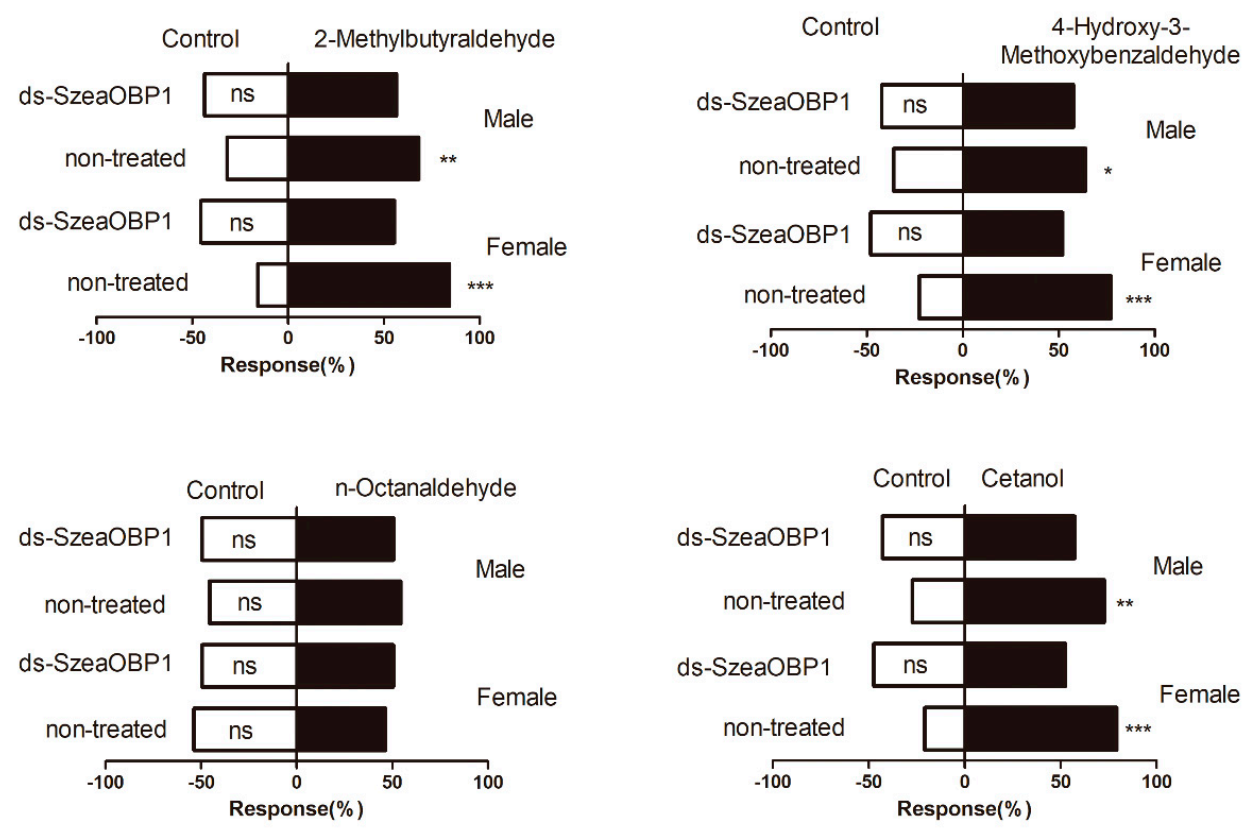

Figure 10. Behavioral responses of Sitophilus zeamais to four selected volatiles in a Y-tube olfactometer after dsRNA treatment. Activity is expressed as percentage weevils responding, and bars followed by different marker indicate significantly different activity of the weevils between the treatments $(p<0.05)$. The mean values shown are predicted values from regression analysis. ' $*$ ' indicates significant differences from even distribution at ${ }^{*} p<0.05$, or ${ }^{* *} p<0.01,{ }^{* * *} p<0.001$. 'ns' indicates not significantly different.

\section{Discussion}

Researchers have used many classic methods for functional research on insect antennae, including the use of scanning electron microscopy to study the ultrastructures of antennal sensilla $[37,38]$. For odorant receptors, Wang and his team used systematic functional analysis across much of the conventional insect odorant receptor repertoire in Xenopus oocytes using two-electrode, voltage-clamp electrophysiology $[39,40]$. The purpose of this study was to explore the functions of OBPs in S. zeamais. 
We used typical methods of reverse chemical communication and molecular biology with volatiles from host plants to study the mutual correspondence between the insects and plants. The specific important roles that OBPs play in insect life were predicted, such as food localization. To truly achieve the purpose of functional research, this feature must be widely applied [41,42]. At the beginning of this study, our laboratory obtained the GenBank transcriptomic dataset from previous work [43]. We also identified 41 OBPs using qRT-PCR analysis and 64 odorant receptors, including odorant co-receptors, and studied these genes in different tissues, including male and female antennae [44]. To predict and conduct research on the specific functions of these proteins, two OBPs, namely, SzeaOBP1 and SzeaOBP28, were used in this study, and detailed analysis was performed. qRT-PCR was used to compare the different expression levels in six different developmental stages of S. zeamais. As expected, different expression levels were observed in the different developmental stages. SzeaOBP1 and SzeaOBP28 exhibited the highest expression levels in antennae compared with other insect tissues in our previous work [43]. Consistent with previously reported results, SzeaOBP1 expression level in FAs remained higher than that in Mas, and SzeaOBP28 expression level in MAs remained lower than those in FAs.

The larvae reared in the controlled closed environment used mostly intact grain as host material to live in, only damaging the grain by biting. In the adult stage, localization of food and selection of spawning sites becomes increasingly important. Prediction of the functional roles of OBPs in the whole olfactory system is important [45]. Therefore, focused research on this aspect is required to prevent grain loss during storage and for pest management. Gene expression ultimately leads to the production of corresponding proteins (or enzymes) [46]. According to the results of qRT-PCR, SzeaOBP1 may be involved in the identification of internal food by LL, and SzeaOBP28 may be involved in the related living conditions of LL and MAs, including food location and mating behavior. Therefore, detected proteins are important markers and indicators of gene expression.

On the basis of the expression results of SzeaOBPs on transcription and protein levels, it can be found that the expression trend of SzeaOBP28 at the level of transcription and protein was basically the same, whereas the expression trend of SzeaOBP1 at these two levels had some differences. Protein synthesis is very complicated, and protein degradation is also a common phenomenon. Even when mRNA expression levels remain high, at the protein level, different trends can be observed, which is a reasonable observation [47-49]. RNA levels and protein levels are often regulated independently. Many microarray/proteomic comparisons have demonstrated low correlation between expression levels or changes in expression levels between protein and RNA, which is a reasonable observation [50,51]. In fact, the results are very interesting and raise questions regarding the biochemical regulation of these specific RNAs and proteins.

Many methods can be used to study the functions of OBPs, but fluorescence competitive binding assays may be the most effective. The fluorescence competitive binding assays showed that each OBP protein binds to these volatiles from the host food source. The volatiles in intact grains are, to a certain extent, different from those in grains damaged by the pest. The odorants tested were distinct between the stored grain volatiles and the green leaf volatiles (GLVs); simultaneously, the differences in odorants between damaged grains and intact grains cannot be ignored. A Scatchard plot was used to examine the binding of the proteins to the odorants [52,53]. The behavior experiment performed with the Y-tube olfactometer simulated, on average, the actual behavior in a technical setting and the fact that the results reflect the actual situation after controlling for external influences. The movement of the insects can be accurately recorded, and the results are reliable. On the basis of the experimental results, the selectivity trend demonstrated by the behavioral experiments was consistent with the trends observed for most molecular biological experiments for a single odorant, as demonstrated by the results for the compounds 4-hydroxy-3-methoxybenzaldehyde. It is generally recognized that behavioral experiments most reliably reflect the actual situation and can be used to validate and reproduce the results of molecular experiments in a live system [54,55]. The results of this study, from the molecular experiments to the behavioral test, demonstrate the functional relationships between the two insect OBPs and the corresponding host plant volatiles in maize weevils. These findings may 
facilitate further in-depth research on boring pests. RNA interference was used as the verification method to verify the function; the results of behavioral experiments showed that the RNAi knockdown individuals displayed behavioral differences between normal insects and dsRNA (SzeaOBP1)-treated insects. With regard to the insect chemical sensory mechanism, the results of this study are not sufficient for elucidation of this mechanism. On the basis of these findings, this approach could certainly be extended to all SzeaOBPs.

Overall, our tests for the ligands and proteins demonstrate that SzeaOBP1 exhibits high specificity for the major component and strong binding of this component, except alkanes, to which this protein did not respond. SzeaOBP28 exhibits a lower binding ability than SzeaOBP1 but remains important for research purposes due to the expression of this protein from the EA to adult stages.

\section{Conclusions}

In conclusion, the relative expression level at transcript and protein of these two SzeaOBPs were tested, we found that they showed different in distinct development stages. The tests for the ligands and proteins demonstrate that SzeaOBP1 exhibits high specificity for the majority component and strong binding of these components, except alkanes, to which this protein did not respond. SzeaOBP28 exhibits a lower binding ability than SzeaOBP1 but remains important for research purposes due to the expression of this protein from the EA to adult stages. The RNAi knockdown individuals displayed behavioral differences between normal insects and dsRNA (SzeaOBP1)-treated insects. We infer that they both have functions in perception and recognition of host volatiles, whereas SzeaOBP28 may also have other functions.

Author Contributions: Conceptualization, Q.T.; data curation, Y.Z., C.S., and Q.T.; formal analysis, Y.Z., D.X., J.W., and Q.T.; funding acquisition, Q.T.; investigation, Q.T.; methodology, C.S., D.X., J.W., and Q.T.; project administration, Q.T.; resources, Q.T.; supervision, Q.T.; validation, J.W. and Q.T.; writing一original draft, Y.Z. and C.S.; writing-review and editing, J.W. and Q.T.

Funding: This work was supported by the National Natural Science Foundation of China (grant No. 31500313), Key Program of Natural Science Foundation of the Higher Education Institutions of Anhui Province, China (grant No. KJ2019A0193), Key Project for Academic and Technical Leader Candidate of Anhui Province, China (grant No. 2017H107), Key Project for University Excellent Young Talents by Anhui Province, China (grant No. gxyqZD2016035), and Innovation Program of Anhui Agricultural University, China (grant No. 2018yjs-6).

Conflicts of Interest: The authors declare no conflict of interest.

\section{References}

1. Sun, L.; Li, Y.; Zhang, Z.D.; Guo, H.W.; Xiao, Q.; Wang, Q.; Zhang, Y.J. Expression patterns and ligand binding characterization of Plus-C odorant-binding protein 14 from Adelphocoris lineolatus (Goeze). Comp. Biochem. Phys. B 2019, 227, 75-82. [CrossRef] [PubMed]

2. Vogt, R.G. Odorant/pheromone metabolism in insects. Chem. Sens. 2006, 31, A7-A8.

3. Vogt, R.G.; Grosse-Wilde, E.; Zhou, J.J. The Lepidoptera odorant binding protein gene family: Gene gain and loss within the GOBP/PBP complex of moths and butterflies. Insect Biochem. Mol. Biol. 2015, 62, 142-153. [CrossRef] [PubMed]

4. Vogt, R.G.; Riddiford, L.M. Pheromone binding and inactivation by moth antennae. Nature 1981, 293, 161-163. [CrossRef] [PubMed]

5. Bruce, T.J.A.; Wadhams, L.J.; Woodcock, C.M. Insect host location: A volatile situation. Trends Plant Sci. 2005, 10, 269-274. [CrossRef] [PubMed]

6. Brito, N.F.; Moreira, M.F.; Melo, A.C.A. A look inside odorant-binding proteins in insect chemoreception. J. Insect Physiol. 2016, 95, 51-65. [CrossRef]

7. Leal, W.S. Odorant reception in insects: Roles of receptors, binding proteins, and degrading enzymes. Annu. Rev. Entomol. 2013, 58, 373-391. [CrossRef]

8. Pelosi, P.; Iovinella, I.; Felicioli, A.; Dani, F.R. Soluble proteins of chemical communication: An overview across arthropods. Front. Physiol. 2014, 5, 320. [CrossRef] 
9. Pelosi, P.; Iovinella, I.; Zhu, J.; Wang, G.R.; Francesca, R. Beyond chemoreception: Diverse tasks of soluble olfactory proteins in insects. Biol. Rev. 2018, 93, 184-200. [CrossRef]

10. Fan, J.; Francis, F.; Liu, Y.; Chen, J.L.; Cheng, D.F. An overview of odorant-binding protein functions in insect peripheral olfactory reception. Genet. Mol. Res. 2011, 10, 3056-3069. [CrossRef]

11. Pimentel, D. World resources and food losses to pests. See Ref. 1991, 37, 5-11.

12. Phillips, T.W.; Throne, J.E. Biorational approaches to managing stored-product insects. Annu. Rev. Entomol. 2010, 55, 375-397. [CrossRef] [PubMed]

13. Liao, M.; Xiao, J.J.; Zhou, L.J.; Liu, Y.; Wu, X.W.; Hua, R.M.; Wan, G.R.; Cao, H.Q. Insecticidal activity of melaleuca alternifolia essential oil and RNA-Seq analysis of Sitophilus zeamais transcriptome in response to oil fumigation. PLoS ONE 2016. [CrossRef]

14. Zanan, R.; Khandagale, K.; Hinge, V.; Elangovan, M.; Henry, R.J.; Nadaf, A. Characterization of fragrance in sorghum (Sorghum bicolor (L.) Moench) grain and development of a gene-based marker for selection in breeding. Mol. Breed. 2016, 36, 146. [CrossRef]

15. Muhammad, F.J.C.; Imran, P.; Faqir, M.A.; Muhammad, A.N. Characterization of sorghum and millet with special reference to fatty acid and volatile profile. Turk. J. Agric. Food Sci. Technol. 2015, 3, 515-521.

16. Sansenya, S.; Hua, Y.L.; Chumanee, S. The correlation between 2-Acetyl-1-pyrroline content, biological compounds and molecular characterization to the aroma intensities of Thai local rice. J. Oleo Sci. 2018, 67, 893-904. [CrossRef]

17. Yang, D.S.; Lee, K.S.; Kim, K.J.; Kays, S.J. Site of origin of volatile compounds in cooked rice. Cereal Chem. 2008, 85, 591-598. [CrossRef]

18. Liyanaarachchi, G.D.; Kottearachchi, N.S.; Samarasekera, R. Volatile profiles of traditional aromatic rice varieties in Sri Lanka. J. Natl. Sci. Found. Sri Lanka 2014, 42, 87-93. [CrossRef]

19. Joseph, A.M. Cereal volatiles, A Review. J. Agric. Food Chem. 1978, 26, 175-178.

20. Phillips, T.W.; Jiang, X.L.; Burkholder, W.E.; Phillips, J.K.; Tran, H.Q. Behavioral responses to food volatiles by two species of stored-product coleoptera, Sitophilus oryzae (curculionidae) and Tribolium castaneum (tenebrionidae). J. Chem. Ecol. 1993, 19, 723-734. [CrossRef]

21. Concepcion, J.C.T.; Ouk, S.; Riedel, A.; Calingacion, M.; Zhao, D.; Ouk, M.; Garson, M.J.; Fitzgerald, M.A. Quality evaluation, fatty acid analysis and untargeted profiling of volatiles in Cambodian rice. Food Chem. 2018, 240, 1014-1021. [CrossRef]

22. Germinara, G.S.; De Cristofaro, A.; Rotundo, G. Electrophysiological and behavioral responses of Theocolax elegans (Westwood) (Hymenoptera: Pteromalidae) to cereal grain volatiles. Biomed. Res. Int. 2016. [CrossRef]

23. Mugula, J.K.; Nnko, S.A.M.; Narvhus, J.A.; Sorhaug, T. Microbiological and fermentation characteristics of togwa, a Tanzanian fermented food. Int. J. Food Microbiol. 2003, 80, 187-199. [CrossRef]

24. Cho, S.G.; Kays, S.J. Aroma-active compounds of wild rice (Zizania palustris L.). Food Res. 2013, 54, $1463-1470$. [CrossRef]

25. Toshova, T.B.; Velchev, D.I.; Subchev, M.A.; Toth, M.; Vuts, J.; Pickett, J.A.; Dewhirst, S.Y. Electrophysiological responses and field attraction of the grey corn weevil, Tanymecus (Episomecus) dilaticollis Gyllenhal (Coleoptera: Curculionidae) to synthetic plant volatiles. Chemoecology 2010, 20, 199-206. [CrossRef]

26. Balakrishnan, K.; Holighaus, G.; Weissbecker, B.; Schutz, S. Electroantennographic responses of red flour beetle Tribolium castaneum Herbst (Coleoptera: Tenebrionidae) to volatile organic compounds. J. Appl. Entomol. 2017, 141, 477-486. [CrossRef]

27. Wang, S.C.; Adhikari, K.; Hung, Y.C. Acceptability and preference drivers of freshly roasted peanuts. J. Food Sci. 2017, 82, 174-184. [CrossRef]

28. Vidya, H.; Hemant, P.; Altafhusain, N. Comparative characterization of aroma volatiles and related gene expression analysis at vegetative and mature stages in basmati and non-basmati rice (Oryza sativa L.) cultivars. Appl. Biochem. Biotechnol. 2016, 178, 619-639.

29. Da Silva, N.C.; Nascimento, C.F.; Nascimento, F.A.; de Resende, F.D.; Daniel, J.L.P.; Siqueira, G.R. Fermentation and aerobic stability of rehydrated corn grain silage treated with different doses of Lactobacillus buchneri or a combination of Lactobacillus plantarum and Pediococcus acidilactici. J. Dairy Sci. 2018, 101, 4158-4167. [CrossRef] 
30. Wang, Y.L.; Chen, Q.; Zhao, H.B.; Ren, B.Z. Identification and comparison of candidate olfactory genes in the olfactory and non olfactory organs of Elm Pest Ambrostoma quadriimpressum (Coleoptera: Chrysomelidae) based on transcriptome analysis. PLOS ONE 2016, 11, e0147144. [CrossRef]

31. Livak, K.J.; Schmittgen, T.D. Analysis of relative gene expression data using real-time quantitative PCR and the 2 (-Delta Delta C (T)) Method. Method Enzymol. 2001, 25, 402-408. [CrossRef]

32. Tang, Q.Y.; Zhang, C.X. Data Processing System (DPS) software with experimental design, statistical analysis and data mining developed for use in entomological research. Insect Sci. 2013, 20, 254-260. [CrossRef]

33. Petersen, T.N.; Brunak, S.; Heijne, G.V.; Nielsen, H. SignalP 4.0: Discriminating signal peptides from transmembrane regions. Nature Methods 2011, 8, 785-786. [CrossRef]

34. Kumar, S.; Stecher, G.; Tamura, K. MEGA7: Molecular evolutionary genetics analysis version 7.0 for bigger datasets. Mol. Biol. Evol. 2016, 33, 1870-1874. [CrossRef]

35. Yusuf, A.A.; Crewe, R.M.; Pirk, C.W. Olfactory detection of prey by the termite-raiding ant Pachycondyla analis. J. Insect Sci. 2014, 14, 53.

36. Takabayashi, T.; Dicke, M. Response of predatory mites with different rearing histories to volatiles of uninfested plants. Entomol. Exp. Appl. 1992, 64, 187-193. [CrossRef]

37. Caetano, R.L.; Carrico, C.; Freitas, D.M.D.; Pinto, Z.T. Ultrastructure of sensilla on antennae and maxillary palps in three Mesembrinellidae species. Rev. Chil. Hist Nat. 2018. [CrossRef]

38. Shen, C.; Zhang, Y.; Xia, D.S.; Wang, J.; Tang, Q.F. Sensilla on the Antennal Funiculus of the Maize Weevil, Sitophilus zeamais (Motschulsky) (Coleoptera: Curculionidae): A Morphological Investigation. Coleopt. Bull. 2019, 73, 443-450. [CrossRef]

39. Carey, A.F.; Wang, G.R.; Su, C.Y.; Zwiebel, L.J.; Carlson, J.R. Odorant reception in the malaria mosquito Anopheles gambiae. Nature 2010, 464, 66-71. [CrossRef]

40. Wang, G.R.; Carey, A.F.; Carlson, J.R.; Zwiebel, L.J. Molecular basis of odor coding in the malaria vector mosquito Anopheles gambiae. Proc. Natl. Acad. Sci. USA 2010, 107, 4418-4423. [CrossRef]

41. Morrison, W.R.; Allen, M.; Leskey, T.C. Behavioural response of the invasive Halyomorpha halys (Hemiptera: Pentatomidae) to host plant stimuli augmented with semiochemicals in the field. Agr. For. Entomol. 2018, 20, 62-72. [CrossRef]

42. Weber, D.C.; Morrison, W.R.; Khrimian, A.; Rice, K.B.; Leskey, T.C.; Rodriguez-Saona, C.; Nielsen, A.L.; Blaauw, B.R. Chemical ecology of Halyomorpha halys: Discoveries and applications. J. Pest Sci. 2017, 90, 989-1008. [CrossRef]

43. Tang, Q.F.; Shen, C.; Zhang, Y.; Yang, Z.P.; Han, R.R.; Wang, J. Antennal transcriptome analysis of the maize weevil Sitophilus zeamais: Identification and tissue expression profiling of candidate odorant-binding protein genes. Arch. Insect Biochem. 2019. [CrossRef]

44. Tang, Q.F.; Zhang, Y.; Shen, C.; Xia, D.S. Identification and expression profiling of odorant receptor protein genes in Sitophilus zeamais (Coleoptera: Curculionoidea) using RT-qPCR. Neotrop. Entomol. 2019. [CrossRef]

45. Pelletier, J.; Bozzolan, F.; Solvar, M.; François, M.C.; Jacquin-Joly, E.; Maïbèche-Coisne, M. Identification of candidate aldehyde oxidases from the silkworm Bombyx mori potentially involved in antennal pheromone degradation. Gene 2007, 404, 31-40. [CrossRef]

46. Tang, B.W.; Tai, S.L.; Dai, W.; Zhang, C.N. Expression and functional analysis of two odorant binding proteins from Bradysia odoriphaga (Diptera: Sciaridae). J. Agric. Food Chem. 2019, 67, 3565-3574. [CrossRef]

47. Hu, Z.D.; Feng, X.; Lin, Q.S. cDNA cloning and characterization of the carboxylesterase pxCCE016b from the diamondback moth, Plutella xylostella L. J. Intergr. Agr. 2016, 15, 1059-1068. [CrossRef]

48. Jin, M.H.; Zhao, X.; Li, G.Y.; Che, X.Z.; Liu, Z.G.; Xue, C.B. Molecular characterization and bioinformatics analysis of a prophenoloxidase-1 (PPO1) in Plutella xylostella. J. Insect Sci. 2016, 8, 1-8. [CrossRef]

49. Pan, Z.Z.; Xu, L.; Zhu, Y.J.; Shi, H.; Chen, Z.; Chen, M.C.; Chen, Q.X.; Liu, B. Characterization of a new CRY2Ab gene of Bacillus thuringiensis with high insecticidal activity against Plutella xylostella L. World J. Microbiol. Biotechnol. 2014, 30, 2655-2662. [CrossRef]

50. Dong, X.L.; Zhai, Y.F.; Hu, M.Y.; Zhong, G.H.; Huang, W.J.; Zheng, Z.H.; Han, P.F. Proteomic and properties analysis of botanical insecticide Rhodojaponin III-Induced response of the diamondback moth, Plutella xyllostella (L.). PLoS ONE 2013, 8, e67723. [CrossRef]

51. Guo, L.; Tang, B.Z.; Dong, W.; Liang, P.; Gao, X.W. Cloning, characterization and expression profiling of the cDNA encoding the ryanodine receptor in diamondback moth, Plutella xylostella (L.) (Lepidoptera: Plutellidae). Pest Manag. Sci. 2012, 68, 1605-1614. [CrossRef] 
52. Xiu, C.L.; Zhang, W.; Xu, B.; Wyckhuys, K.A.G.; Cai, X.M.; Su, H.H.; Lu, Y.H. Volatiles from aphid-infested plants attract adults of the multicolored Asian lady beetle Harmonia axyridis. Biol. Control 2019, 129, 1-11. [CrossRef]

53. Christensen, S.A.; Nemchenko, A.; Borrego, E.; Murray, I.; Sobhy, I.S.; Bosak, L.; DeBlasio, S.; Erb, M.; Robert, C.A.M.; Vaughn, K.A.; et al. The maize lipoxygenase, ZmLOX10, mediates green leaf volatile, jasmonate and herbivore-induced plant volatile production for defense against insect attack. Plant J. 2013, 74, 59-73. [CrossRef]

54. Islam, J.; Dhiman, S.; Tyagi, V.; Duarah, S.; Zaman, K.; Chattopadhyay, P. Behavioural and electrophysiological responses of mosquito vectors Aedes aegypti, Anopheles stephensi and Culex quinquefasciatus to an ethyl ester: Ethyl 2-aminobenzoate. J. Insect Behav. 2017, 30, 343-358. [CrossRef]

55. Morawo, T.; Fadamiro, H. Identification of key plant-associated volatiles emitted by Heliothis virescens larvae that attract the parasitoid, microplitis croceipes: Implications for parasitoid perception of odor blends. J. Chem. Ecol. 2016, 42, 1112-1121. [CrossRef]

(C) 2019 by the authors. Licensee MDPI, Basel, Switzerland. This article is an open access article distributed under the terms and conditions of the Creative Commons Attribution (CC BY) license (http://creativecommons.org/licenses/by/4.0/). 